\title{
A MOTOR THEORY OF RHYTHM AND DISCRETE SUCCESSION. II.
}

\author{
BY R. H. STETSON,
}

Beloit College.

\section{Nature of the Unit-Group.}

Since accentuation and subordination are contributed in rhythmizing a perfectly uniform objective series, they have always been considered important, and perhaps essential elements in rhythmic perception. The most fundamental type of subordination with accentuation is to be found in the unitgroup.

Many different types of feet in verse, of measures and figures in music, and of 'groups' in psychology have been named and described. The musical measure is manifestly a secondary and not a primary type of grouping, and the 'groups' of the psychologist have usually been arbitrary logical constructions, so that a classification of unit-groups need include only poetic feet and musical figures. Despite the many combinations named, most recent writers are inclined to reduce the types of feet to four: iambic, trochaic, dactylic and anapestic. ${ }^{2}$ Some writers add amphibrachic, but it is only a variety of the dactylic. All the numerous forms of feet occasionally given can be separated into these elementary forms. A consideration of musical figures shows that these forms of poetic feet cover many of the varieties of musical figures. The trochee represents such forms as $\mathcal{J}, \delta, \delta$, and the more unusual $£ d$. The iamb represents the 'dotted-eighth-and-sixteenth forms, $\sqrt{2}$. (usually written $\sqrt{. J}$ ), most grace noles, and the unusual $\delta$ and $\delta$. The dactyl represents the triplet $\sqrt{d}$ and the unusual figure $\int$ in most cases this notation

'Cr. Gummere's Poetics. 


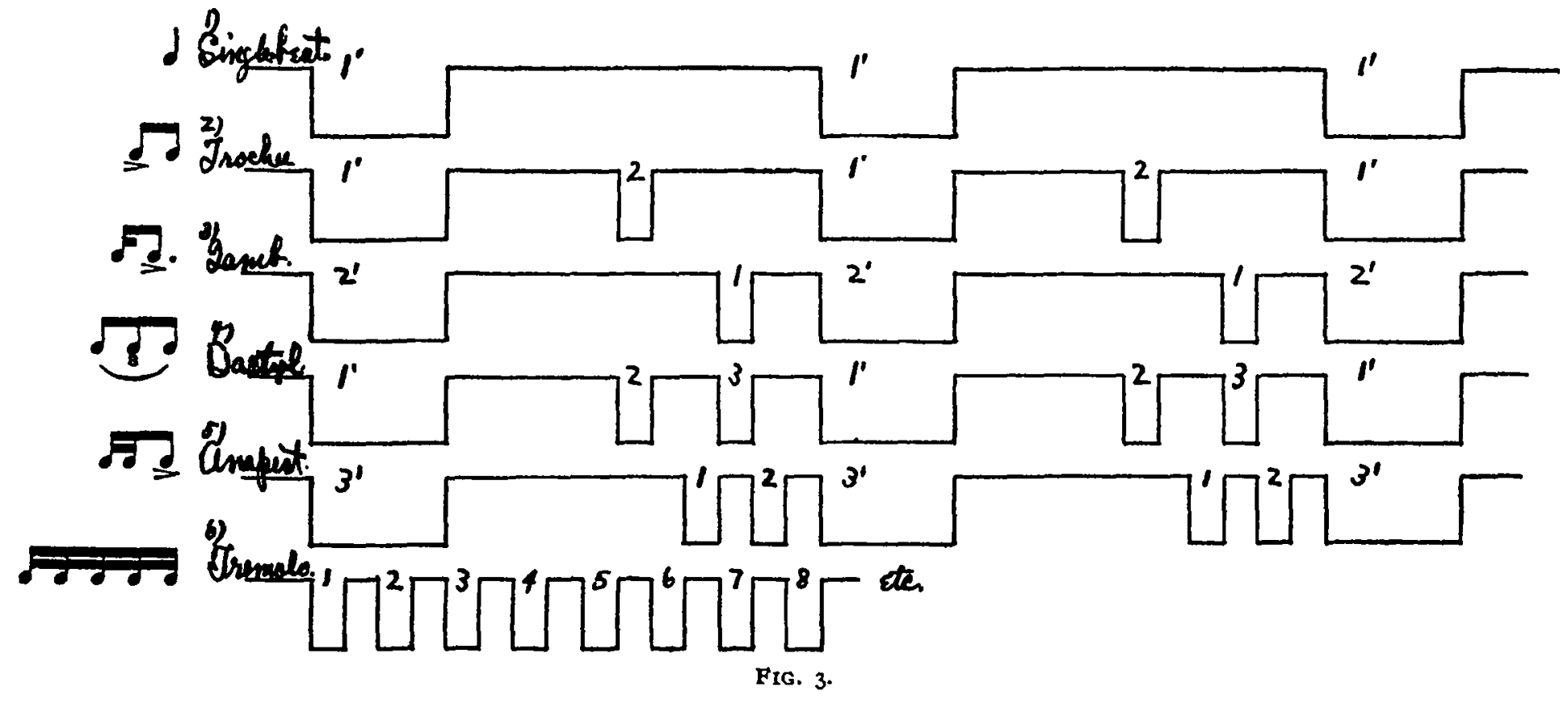


indicates not a unit-group but a compound of $\oint$ and $\Phi$ ). The reverse of this last type $F$ is represented by the anapest, but it is worth noting that in music where this form occurs asa true unit-group (the notation usually represents a compound) it becomes simply a variety of the iambic $\delta \_$. There remain two unit-groups in music not represented by the poetic feet mentioned; these are the single note $d$, $d$, etc., the trill or tremolo, and the rapid run. The trill or tremolo and the rapid run all represent one type of figure the number of constituent notes is indefinite, and the intervals between the constituents are all equal.

Below is given the complete list of unit-groups which must be considered; the time relations are represented and the width of the depressions indicates the length of time that a finger will remain on a key, or a syllable will be vocalized; the groups are arranged so that the accented beats, the convenient reference points, coincide.

The length of time that the finger remains on the key is really a function of the energy of accent; the untrammeled movement would give the form in Fig. 4. (Cf. Fig. I.)

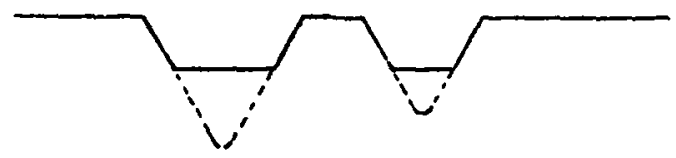

Fig. 4 .

There is an upper and a lower limit to the rate of succession at which grouping into unit-groups is possible. The lower limit is variously estimated at $\mathrm{I} .5-3 \mathrm{sec}$., $40 \mathrm{M},-20 \mathrm{M}$. As this interval of $1.5-3 \mathrm{sec}$. represents the longest interval during which a rhythmic movement can persist, it is obvious that a group of twice that length (the simplest possible two-group) would be an impossible rhythm; therefore, at the lowest rate of rhythmic succession no grouping is possible, i. e., the group must consist of one beat. When the rate of succession is increased to $4^{-8}$ per sec., the interval and the accent again become uniform and there is no grouping possible. The single 
beat, then, and the tremolo are forms of the unit-group which occur at the upper and lower limits of rhythmic succession, and they are evidently not produced by the grouping activity as it occurs in the case of the iamb, trochee, dactyl (and anapest).

The notion that the muscular tensions of a movement-cycle such as that previously described must be responsible for the grouping of the unit-group ${ }^{1}$ is too general as it stands. Miner ${ }^{2}$ suggests that the fusing of reactions to stimuli in a muscle contracting and relaxing at certain rates is the cause of the grouping. Such a fusion of contractions is observed in the action of a single muscle, wheras the simplest rhythmic beat is produced by a complicated movement-cycle; the fusion would in no wise explain the characteristic structure of the unit groups. Moreover, if the rhythm is due to the movement, such a fusion might explain the omission of the subordinate beats, but not their grouping.

The Wundtian explanation that the beats of a group occur during a wave of attention, if translated into terms would mean that a secondary rhythmic movement occurs, and the beats of the primary movement included in each simple movement-cycle of the secondary rhythm are thereby grouped together. Such a combination of rhythms must actually occur in music, but it will not explain the unit-groups. First, in music where it does occur we do not have the temporal and accentual relations of the unit-groups ; ${ }^{3}$ second, with such a grouping mechanism, we should expect an indefinite number of beats in the unit-group (in music we do actually have an indefinite number of beats of one rhythm occurring during a single beat of the secondary rhythm); there would be no reason why the type of grouping at the fastest rate of succession should change, as it does when the tremolo form of rhythm appears.

Accentuation and subordination with the involved temporal relations are not peculiar to rhythmic movement. Wherever complicated movements occur we have such a grouping. Individual letters of words written with a pen, syllables and words

' 'Rbythm and Rhymes,' loc. cit., p. 455 ff.

2 Miner, J. B., 'Motor, Visual and Applied Rhythm,' PSY. REv., '03, Mon. Sup. 5 , No. 4 , p. 34.

'Cf. 'Combined Rhythms,' below. 
written at the typewriter, but best of all spoken words, illustrate this grouping of a set of movements about a single definite accent. As one writes the word 'the' at the typewriter, the form is $\checkmark \checkmark \checkmark$ with a definite accent on the middle letter. In the syllable ' ing,' the form is $\checkmark \checkmark \longleftarrow$ with the accent on the last letter. In writing the letter ' $a$,' the movements are subordinated to the down stroke at the side of the loop. But speech best illustrates such groupings. Every English word of more than one syllable constitutes a whole; it is in a sense a single movement, and yet it contains distinct pulses, and one of these pulses is accented and is much longer than the rest and is, in a sense, the center of the word. The uttering of the word is a muscular process and the varying lengths of the syllables are due to the accentual form. The accent itself is made by an increased contraction of the muscles of expiration; in fact, the whole expiratory stress seems to center in the accent. In the case of the movements in writing with the pen, observation shows that the subordinate strokes are performed by the fingers, while a stroke which has the accent is produced by the hand, or the hand and arm as well as the fingers. These strokes of the fingers, and of the hand and arm are all parts of the same movement; the muscles act together, at points all the muscles are working together, but at other points, the more mobile sets execute semi-independent movements while the slower sets are preparing for the next main contraction at the principal part of the movement. Most of our movements show this semi-independent, semi-synergic character of the various parts and muscle-sets of the organ involved. In the case of the vocal organs, the more mobile parts are the organs of mouth and throat, the slower are the muscles of expiration. In wielding any instrument or tool, the hands and fingers are performing a variety of auxiliary movements during the slower moving of the fore-arm; the upper-arm and shoulder are less used than the fore-arm for rapid parts of the movement. In walking or executing the pedale part of an organ score, the foot and leg show the same system of main and auxiliary movements as the hand and arm. In such cases we have a mechanism of subordination and accentuation which was developed long before 
rhythmic movement made demands on it. It is important to note in all the cases mentioned of auxiliary movements that they are in no sense separated from the process of the whole movement; not only are they means to the one end of the general movement, but it is impossible to say where they begin or where they end, and at many points, the muscles are all contracting or relaxing in one common wave of innervation.

Rhythm is produced by a series of single strokes composing a movement of the type just noted; the fingers and hand, the hand and arm, the vocal organs, can all execute rhythmical movements. Granted that one of the beats be accented, and of necessity other muscle-sets will come into play with the accent, partly because of the tendency of innervation to irradiate to related muscles, partly because the increased strain will necessitate further bracing contractions (the 'pseudo-antagonistic' coordination). ${ }^{1}$ These added muscle-sets will work as a part of the movement, and yet their rate of easy contraction and relaxation is much less than that of the more mobile muscle-sets involved. Even the different fingers of the hand show different degrees of mobility. ${ }^{2}$

While these muscles which have to do with reinforcing the accented beats are working slowly, the more mobile muscle-sets execute the intervening beats with less force and with less amplitude of movement; this beating of the unaccented elements is not a separate process, however; the minor muscle-sets unite with the major muscle-sets to make the accented beat, and many of the same muscles which are active during the accented beat must take part during the unaccented beats $(e . g$., the muscles which brace and guide the limb as a whole). (Cf.Fig. 5.) The process remains one movement, just as the letter in writing, the word in speaking, the complex movements in striking a chord at the piano or in turning a door-knob are all one movement. But why should the accentuation develop in a series? If the rate of a very slow series be increased, or if the movement of any series be intensified, other muscle-sets will be inevitably

${ }^{2} C f$. Beevor, C. E., 'Muscular Mechanism,' Lancet (London), 'o3, I, 13571360; also Müller, R., 'The Mosso Ergograph,' Phil. Siud., 17, S. r.

'Reif, 0. ., 'Ueber Fingerfertigkeit beim Klavienspiel,' Ztsckr. f. Psy. u. Phys. d. S. org., ' $\infty$, 24, S. 352 . 


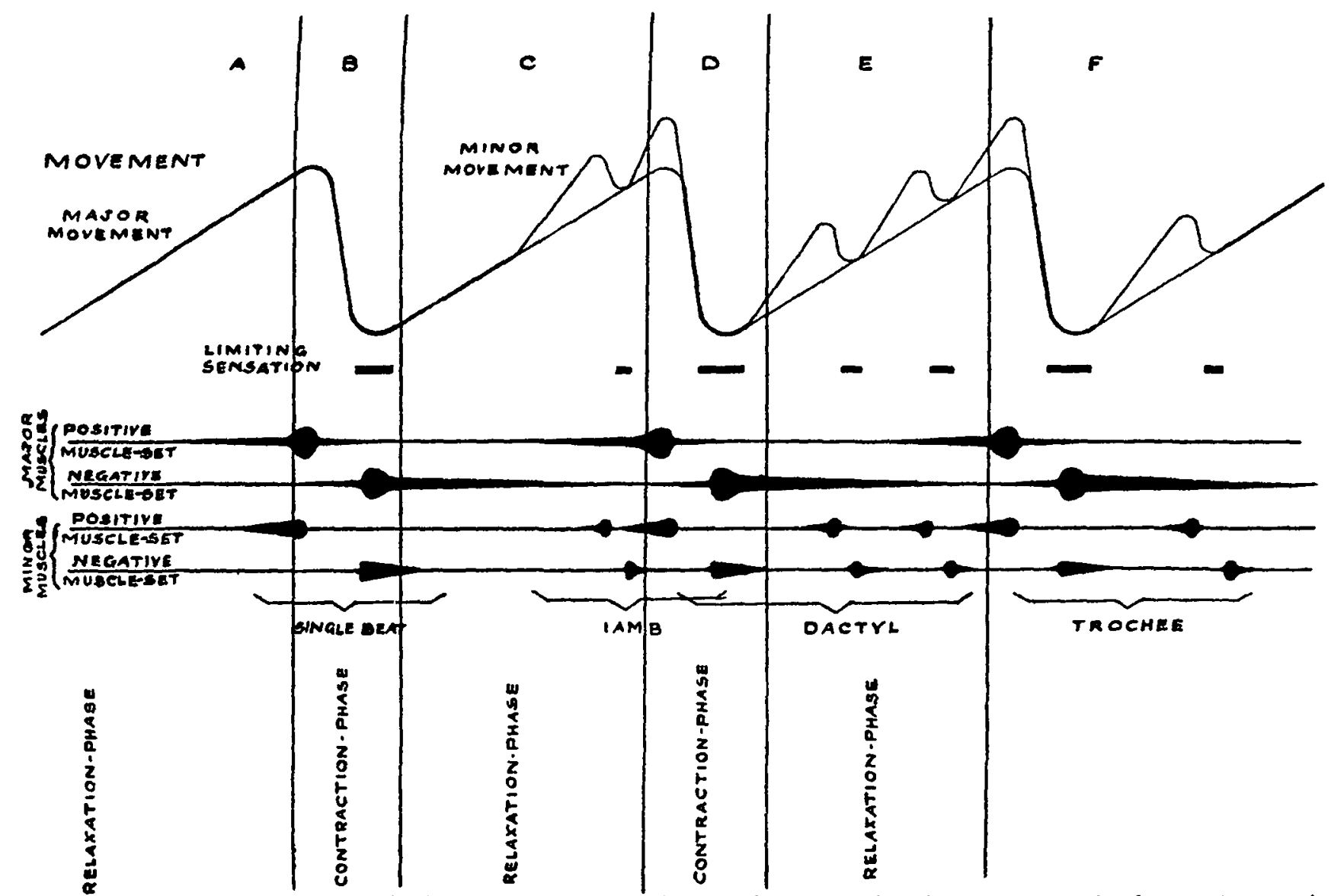

Fig. 5. Contraction of the muscles is represented by the increase in width, relaxation of the muscles by the decrease in width of the line representing the muscle-sets. 
involved, and as these work at different rates, the accentual type of coördination previously developed by all sorts of movements is the one natural and easy way for them to work together. One may say that the unit-group is the form in which the various muscle-sets and segments of a limb or organ can all work together freely and easily in a single-movement cycle.

What are the conditions in which the parts of a complex movement seem continuous, and the movement therefore a whole? Rieger ${ }^{1}$ notes that in ballistic movements the backstroke is psychologically continuous with the beat-stroke and with it makes up a unity. When a new movement is learned its parts are executed separately and are distinct; the muscular tensions die out, and each is a new movement. Even when the movement comes to be executed more rapidly, as long as there is hesitation between the parts, the movement does not seem continuous, even though the muscular tensions are maintained during each slight pause. When the movement finally becomes continuous, the muscle-sets are acting reciprocally and the muscle-tensions are constantly changing; the parts of the movement 'flow into each other.' As long as the tensions are changing between the muscle-sets we have continuity. When the tension between the muscle-sets is stable, the limb is poised and the movement is at a standstill and there is an impression of suspense, of delay, or of 'pause,' but not of continuity. The degree of tension in this condition of poise and standstill determines the intensity of the feeling of suspense and delay. When the tensions between the muscle-sets die out at the close of the movement, we feel that the movement is passed and done; there is no feeling of suspension or pause. In the movement-cycle previously described there is but one point where normally the limb is poised; at the end of the back-stroke, and just before the next beat-stroke, records show that there is a moment when the limb is at a standstill. There may be a suspension and a poised condition anywhere in the relaxation-phase. The conditions of the beat-stroke preclude any condition of equilibrium and 'pause' in the contraction-phase. If, then, the auxiliary movements 'flow into' the movement of the accented beat, $i$. e.,

' Loc. cit., S. 389 . 
if the transition from the subordinate beat to the accented beat (or vice versa) takes place with continually changing tensions without equilibrium occurring between the various muscle-sets involved, the subordinate movement will be continuous with the accented stroke. If at any point during the whole unit-group the conditions of muscular tension are stable and the limb comes to a stop, there will be at that place a 'pause' or suspension.

The observed structure of the unit groups (cf. Fig. 3) may be explained by the grouping process just outlined. In the case of the single beat, the beats are too far apart to be grouped; by hypothesis they are as far apart as heavy accents made by the slowest moving muscle-sets can occur.

The tremolo does not show a type of grouping like that of the other four unit groups. At the rate of $4-8$ per sec., interval of 125-250 sig., a single member is beating as rapidly as possible; by combining two or more members as the fingers in piano playing the rate may be as rapid as c. 8-r8 beats per sec., interval $125-55$ sig. ${ }^{1}$

It is apparent that the speed with which a series of beats can be produced by a single member is about half or a little less than half the maximal speed of a series of beats produced by the combination of two or more members. In a rapid trill at the piano the first finger is raised while the second delivers its blow, and the second is raised when the first descends, so that the interval between the beats of the trill is actually the duration of a single stroke. The duration of the beat-stroke in the records taken ( $c f$. Table I.) is from 50-100 sig. If the interval between a trill or a run has the duration of a beat-stroke of the record, the rate for the series of beats would be from ro-2o beats per second. The maximal rate is not determined by the number of members employed, as Reif assumes, but by the minimal interval, the duration of the beat-stroke. The beat-stroke is a process during which the judgment is very uncertain, and a coördination by which a second member shall strike a beat at the end of the first third or half of the beat-stroke is impossible. In beating a series at a maximal rate of succession, there are two and only two events which can act as clues to the reciprocating muscle-

${ }^{1} C f$. Reif, loc, cit., and Rieger, loc cit. 
sets : the sudden contraction of the positive muscle-set at the beginning of the beat-stroke, this is the cue for the contraction of the negative muscle-set which brings the beat-stroke to an end and throwe the member back to the point of starting : second, this contraction of the negative-set becomes the cue for the positive muscle-set which catches the limb at the end of the back-stroke and throws it into a second beat-stroke. Both movements are ballistic and of nearly equal duration, if one member or two members are producing the series, but if three or more members are employed as the fingers in a piano run, the back-stroke of each member may be slower and not of the ballistic type. It is obvious that in a trill or tremolo executed by one or two members, there can be no accentuation, for an accentuation would mean an increased time to recover from the heavier contraction, and would drag into play slower acting muscles with which the rapidly acting muscle-sets could not fuse at the accented beat without being delayed. In a run accentuation may be possible because each member works more slowly, but the working of the slower auxiliary muscles is so distinct from the process producing the run that the form of an accented run is practicable only where two distinct rhythmic processes are present. It is also obvious that in the rapid succession of the trill, tremolo or run there will be continuity between the beats; they will all seem parts in the same movement, for at no point in the process is there opportunity for stable tensions and a poised condition. The tensions must always be changing rapidly and the movements ' flow into each other.'

In the case of the iamb, trochee, dactyl (and anapest) the temporal relations are determined by the events in the complex movement producing the group. There is a long interval after the accent because the heavy contraction of all the muscles concerned takes place at this point and time is needed for their relaxation. During the remainder of the group, the larger, slower muscle-sets (often these make up the musculature of the proximal segments of the limb) relax and readjust themselves for the next accent, while the more mobile sets (usually of the distal segments of the limb) beat the subordinate elements of 
the group with less force and with less amplitude of movement; their action is not independent of the action of the larger, major sets on which they depend for support and control, and with which they merge at the general pulse of the accent.

If movements are prescribed for a subject, in which distal and proximal strokes of the limb are alternated, the unit-groups can be produced artificially.

One very interesttng set of records shows the tendency of the muscles to rearrange themselves in their normal coördinations of major and minor muscle-sets in the movement-cycle of the unitgroup. The form chosen was the triplet to which both hand and foot contributed beats. This form is not at all difficult when the order is foot, hand, hand, etc., $\{\delta$, where the slowmoving muscle-sets of the foot become the major muscles giving the accent. But the combinations hand, foot, foot $f^{3}$ and foot, hand, foot $\{\delta$, and hand, foot, hand $\delta \&$ are very difficult and awkward.

Two subjects who had had some practice in using the foot for independent rhythms were asked to beat the forms. The records of Table III. show that it is very difficult to keep the accent on a hand beat, and to keep the beats even approximately equidistant. The direction of the irregularity is important. In every case the interval from hand-beat to foot-beat is shortened, and the interval from foot-beat to hand-beat is lengthened. The hand-beat becomes a mere appendage to the foot-beat, and the foot-beat assumes its normal function of giving the accent. This tendency is carried farthest in the records of St.

The short element in the trochee is at some distance from the accented element because it occurs afier the pulse of the accent; all the muscle-sets have given a heavy beat and some time is required before the mobile sets, though they work continuously, can produce the subordinate beat. The short element of the trochee is heavier (and therefore longer) than the short element of the iamb, because it occurs in a part of the group- 
TABLE III.

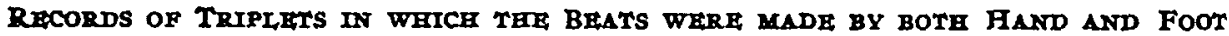

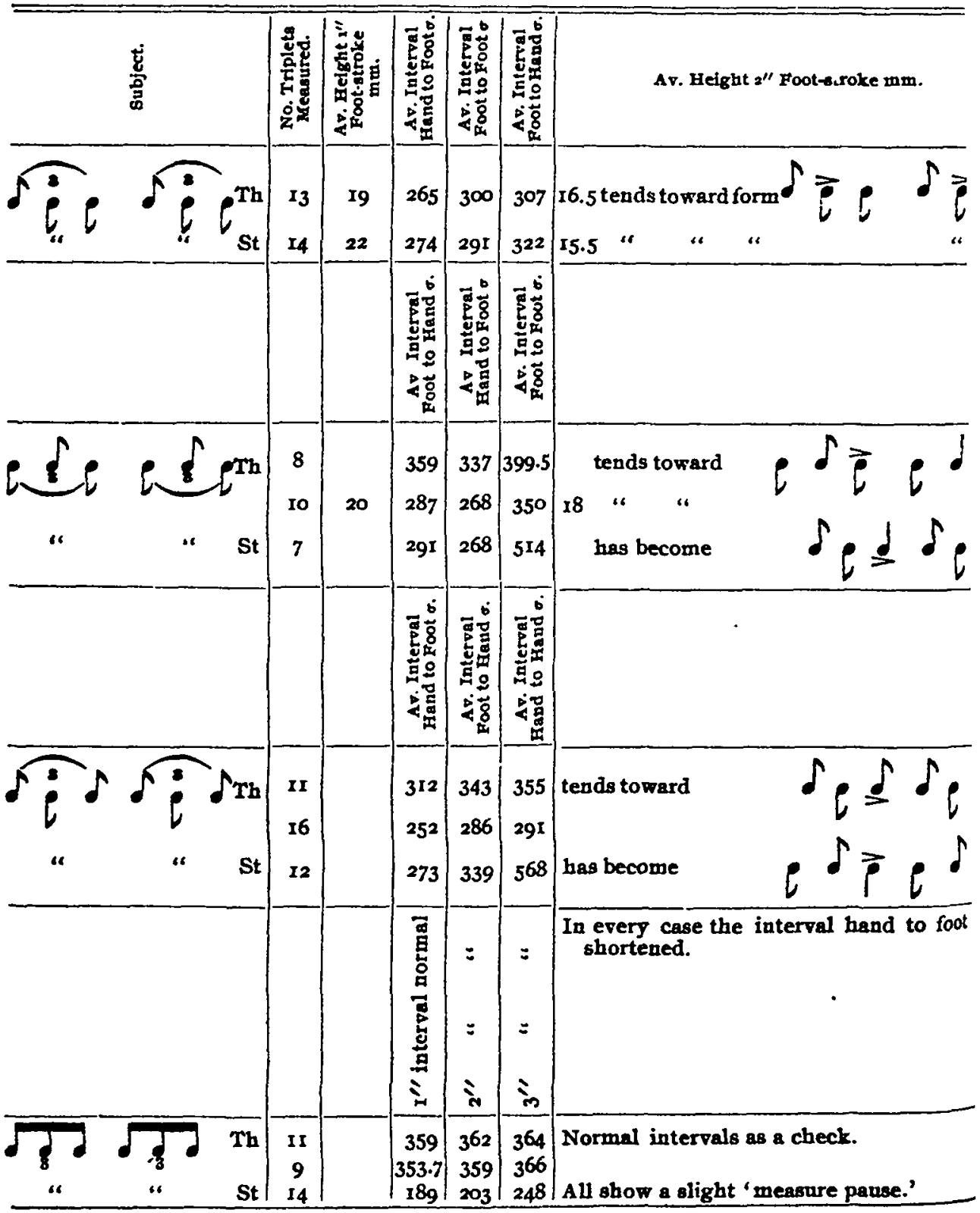


movement where the muscles as a whole are more or less tense. The short element of the iamb is very light (and therefore very brief) and very near to the accented element, because it occurs before the accented element and is therefore in a part of the group-movement where the tensions are least (poised condition of the slower muscles just before the beat), and as there is only the relaxation from its own light movement to intervene before the accent, the interval separating it from that accent is very short. The normal dactyl has one short element in the place of the short element of the trochee, and one in the place of the short element of the iamb. (The form fied trochee in which the short element is reduplicated. In the same way, the temporal values of the anapest point to its being a modified iamb. Reduplication of this kind is very common in music ( $c f$. the iamb with triple reduplication in Mendelssohn's 'Funeral March' groups just described are capable of considerable variation. An increase of the weight of accent will tend to shove the short element of the trochee farther and farther from the accented element. The lifting of the limb to an unusual height to produce accentuation will tend to make longer the interval between the short element and the accented element of the iamb.

But the conditions in which the movements of the unitgroups will be continuous, and the group therefore a unity, limit the position of the short elements. That the movement of the more mobile muscle-sets shall be continous in the interval between the general pulse of the accent and the beat-stroke of the short element, it is essential that the muscular tensions change constantly, that the movement keep going on; there must be no time of stable tension between these more mobile muscle-sets, no ' pause,' between the accent and the short element. Thus the short elements of the unit-group appear as appendages to the main movement of the accent. The footpause, where there is a foot-pause, appears at the point of stable tension and poise in the relaxation-phase. The iamb and the trochee usually have such a pause. In the normal dactyl it 
occurs between the two short beats, but it may be absent. The form of dactyl with the pause at the end of the foot is not strictly a dactyl but a reduplicated trochee. An apparent pause after the two short elements (i. $e$, , what seems a pause on the records) is sometimes due to the lifting of the limb for the next heavy accent.

The characteristic affective tone of the simple rhythms must be due to the type of movement of the unit-groups. The short element of the iamb occurs at a point in the general movementcycle where it acts as a sort of anticipatory stimulus and serves to emphasize the accented beat; the contrast, too, between its light short- and heavy long-element is greater than that of any other group. Perhaps this has something to do with the heavy, definite, final character of the iamb. The short element of the trochee occurs during the earlier part of the relaxation process at a point where it must stimulate this relaxation, and tend to shorten the total group-movement. ${ }^{1}$ This may be a clue for the reason of the bouyant, non-final character of the trochee. The dactyl has all the movements possible to a simple unit-group; it is the most closely knit and most continuous of all the forms of grouping, and this doubtless has something to do with the steady, rapid, full impression that it makes upon us.

Mention has already been made of groups in which the different parts of the group were produced by different members as the fingers in piano playing, and the question arises how one is to explain the continuity and unity of movements involving separate members. An easy way out of the difficulty would be to assume a rhythm-apparatus of invisible muscle-sets which produces all rhythms and directs the action of separate members engaged in the production of simple rhythm-groups. Certainly there must be such a mechanism when we listen to a sound series and rhythmize it. While one cannot deny that such a method of directing separate members is possible, it seems more probable that all muscle-sets, whether or not they happen to belong to segments of the same limb may produce movements which are continuous to consciousness, and which therefore come directly to a unity of movement without the intervention

${ }^{1}$ Cf. experiments of Cleghorn, A., Am. J. Phys., '98, 1, p. 336. 
of another process. We have such unified movements often in non-rhymithical experience. Speech, riding a wheel, walking, are examples of such unified movements involving different members. The unity of an act seems to depend on the continuous character of its constituent movements and on the purposive habit which gave rise to it, rather than on the anatomical relation of the parts involved.

\section{Perceived Rhythms.}

Thus far mention has been made of rhythms only as they are produced; it remains to consider the process by which the rhythm-movement is induced in the act of perceiving rhythms. Every sound must be assumed to cause a movement involving the general musculature; if the series of sounds occurs at regular intervals, the movements will take on the coördination which answers best to the objective form of the series. The slower muscle-sets roused will adjust themselves to beats occurring at convenient intervals, and the intervening beats will occasion contractions of auxiliary and more mobile sets which thus produce the subordinate beats of the unit group. In the establishing of this coördination, the occurrence of a sound slightly before or after one of the pulses of the incipiently coördinated movement will not destroy the coördination,' ${ }^{1}$ but will alter it slightly.

In case the sound which falls on the accented beat does not have an intensity corresponding to the intensity of the beat, the movement-cycle itself contributes the requisite vividness. This is one of the most common illusions occasioned by rhythm. This universal ' subjective accentuation' goes to show that in the rhythmic perception the vividness of the various beats heard is determined by the motor process at the basis of the rhythm-perception. The only way that the subjective character of the phenomenon can be verified is by shifting the accent from point to point in the objective series, as can be done at will in many cases (ticking of a clock, metronome, etc.).

Not only the degree of vividness of the different beats, but

'Cf. Hofbauer' Zusch experiments, loc. cit., and 'Rhythm and Rhyme,' loc. cit., p. 457 . 
also the position in the objective time series in which the sounds occur may be modified by the rhythm process. This 'temporal displacement' has often been noted. Its explanation is important to a thoroughgoing theory of rhythm. If a series of equidistant sounds like the ticks of a metronome are heard, the observer may phrase them into iambs, trochees, or dactyls, as he chooses. To the ear, the choice seems to affect merely the vividness of the beats. But if the observer taps a key at each beat of the metronome, it will be found that in the case of the iamb he always misplaces the beats; often the same thing happens in the case of the trochee and dactyl. Because of the influence of the rhythm process, the observer does not hear the beats where they actually occur. In the case of the iamb he always hears the beat which he makes subordinate nearer the accented beat than it actually is in the objective clicking of the metronome. Table IV. is made up from the records of two subjects who listened to the equidistant and uniform sounds of a metronome grouping them either as iambs or trochees, tapped a key with each beat of the metronome, and beat with the foot once during each iamb or trochee. All three series were recorded.

In the case of the accented beat of the iambs, it will be seen from the table that the three events, the sound, the tap of the

\section{Table IV.}

Thmororax, Disptachmant in Percetving Untpork Sound-Shrias.

Record of tapping with the hand in unison with a series of equidistant clicks which the subject grouped in different ways. At the same time the foot beat once for each anit-group. The objective sound series, the tapping of the hand and the beating of the foot were all recorded.

\begin{tabular}{|c|c|c|c|c|c|c|c|c|}
\hline 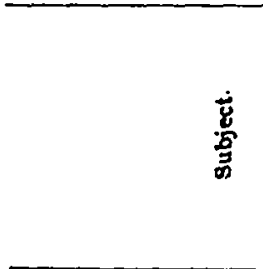 & 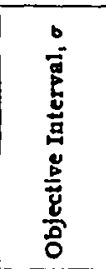 & 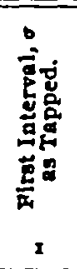 & 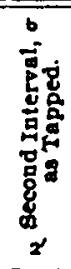 & 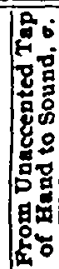 & 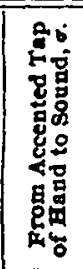 & 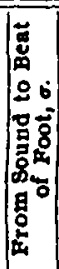 & 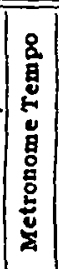 & \\
\hline 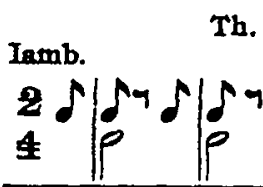 & c. 1000 & $\begin{array}{r}870 \\
890 \\
520 \\
970 \\
1030\end{array}$ & $\begin{array}{r}970 \\
1050 \\
1030 \\
1030 \\
940\end{array}$ & $\mid \begin{array}{c}32 \\
16 \\
26 \\
26 \\
0^{1}\end{array}$ & $\begin{array}{c}0 \\
0 \\
-15 \\
0 \\
9.7\end{array}$ & $\begin{array}{r}0 \\
26 \\
13 \\
0 \\
32\end{array}$ & 160 & $\begin{array}{l}\text { Unaccented tap held down } \\
\text { until beck-stroke of foot. } \\
\text { "c } \\
\text { "6 } \\
\text { "6 }\end{array}$ \\
\hline
\end{tabular}



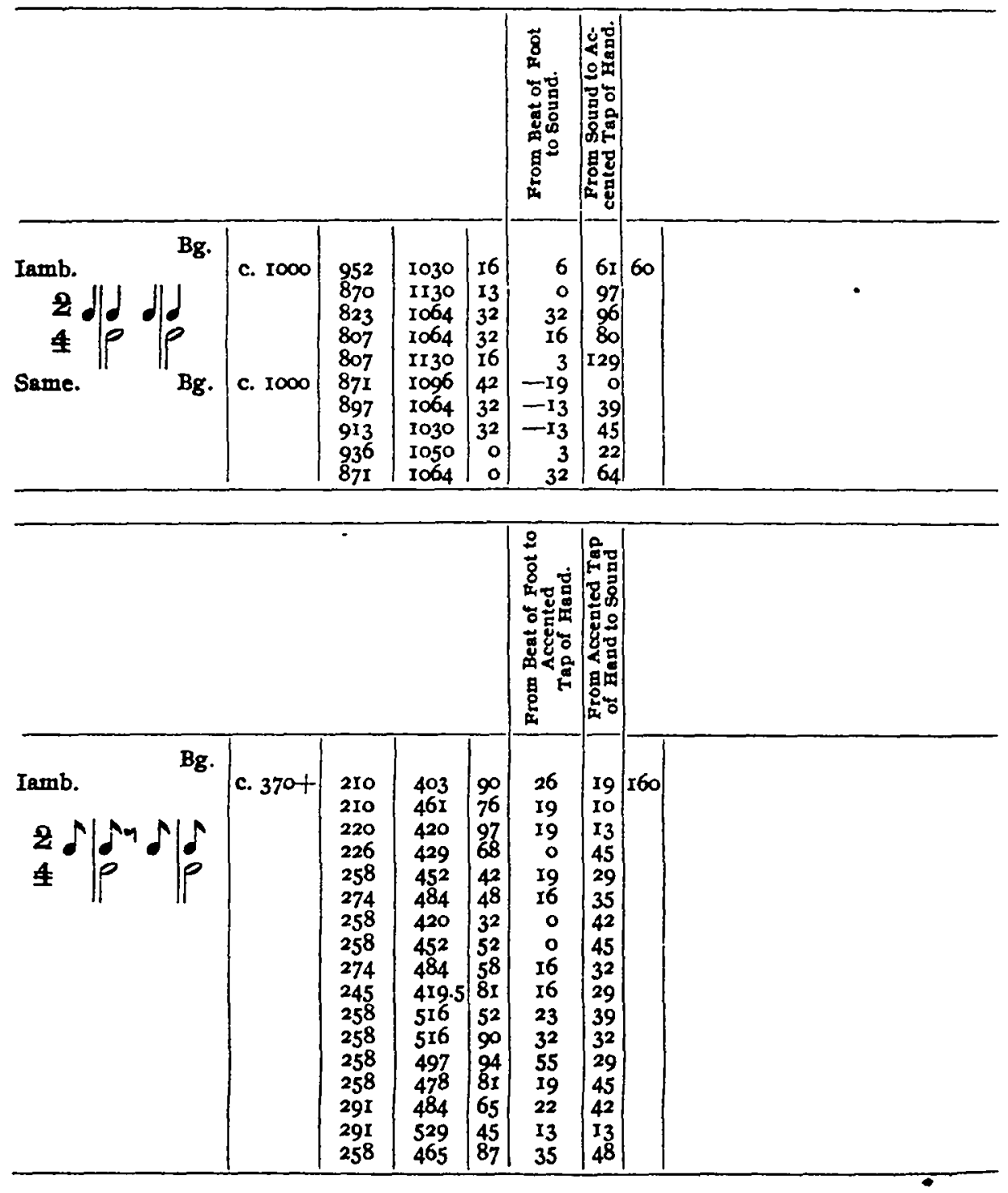

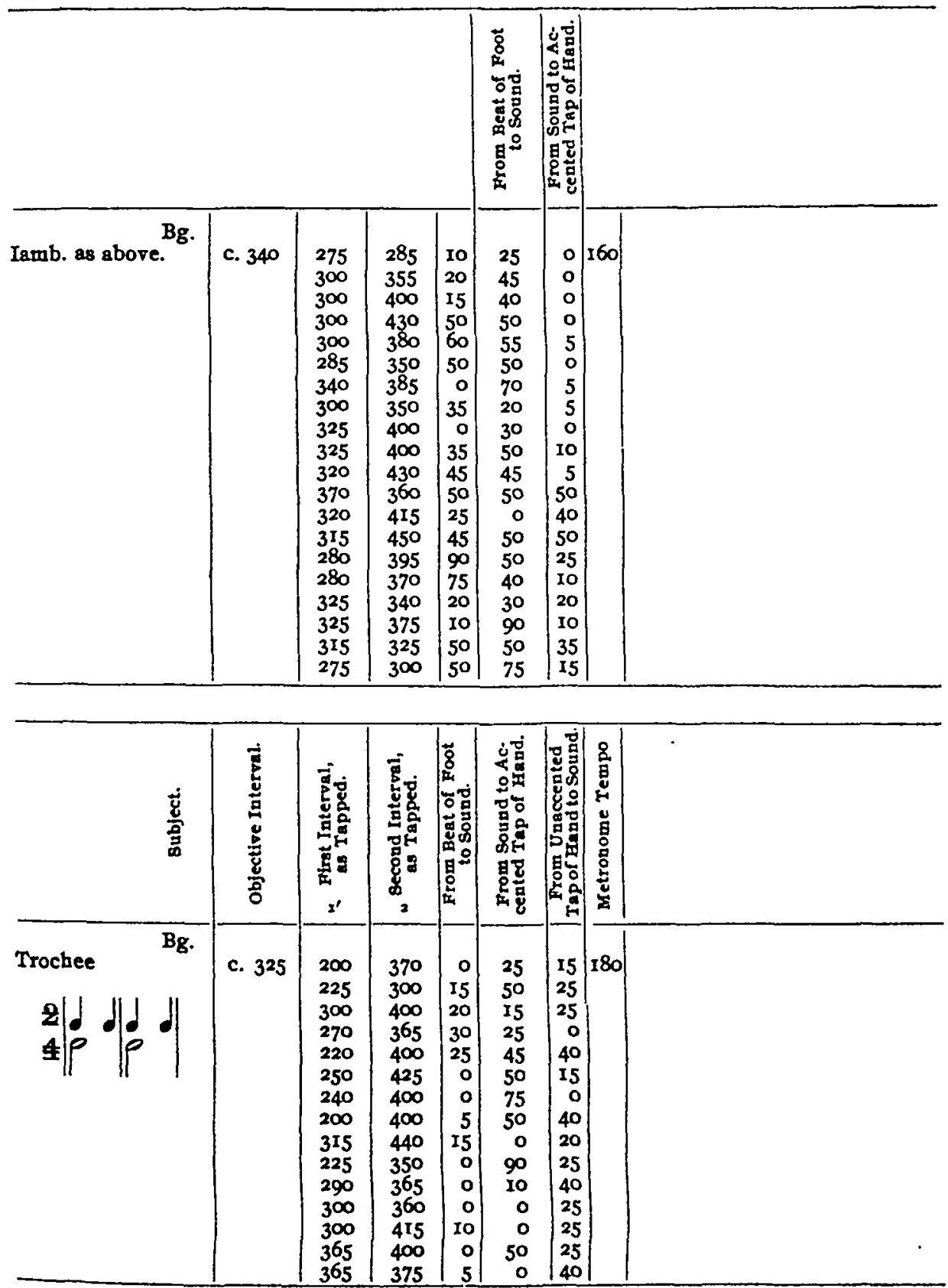

Other records of Bg. show trochee grouping without displacement. 
finger and the beat of the foot seldom coincide exactly. Often the beat-stroke of the finger seems to continue the beatstroke of the foot for a few sigmas. But the metronome sound always falls somewhere within the contraction-phase, usually toward the close of the limiting sensation of the hand or foot or both. The sound at the accent never occurs as early as the beginning of the beat-stroke of the foot. But it is very different in the case of the subordinate beat. Here the sound always occurs before the tap of the hand, and it is mainly this delay of the tap at the alternate unaccented beats which produces the difference of the intervals; it is here that the shifting, the 'temporal displacement' occurs. Figure 6 illustrates the relation between the actual series and the perceived series.

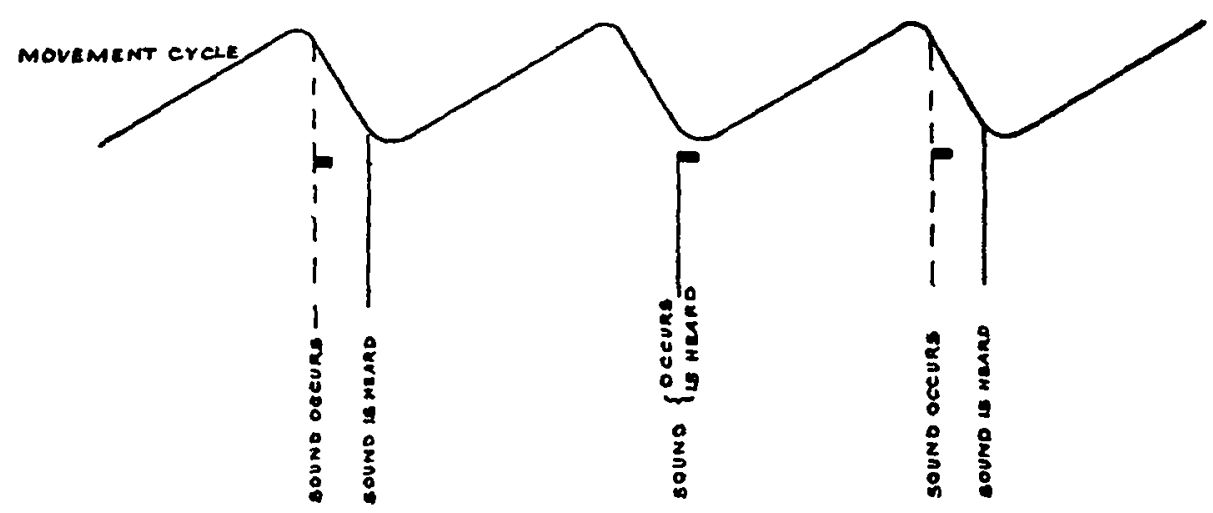

Frc. 6.

In reviewing the records at various tempos of both subjects, it will be seen that the amount of displacement is about the same at all rates. It is not possible to shift the accent more at the rate of $I$ beat per second than it is at the rate of 3 beats per second, although the effect of the same amount of displacement is much more apparent in the case of the rapid tempo. This displacement at the subordinate beat varies from about 25 to Ioo sig. As the sound precedes the tap of the hand by this amount, it must be that the sound comes at or just after the beginning of the beat-stroke of the finger, whatever the interval between the sounds. The conclusion is inevitable in the case of the groupings given in Table III., that a sound heard during 
the beat-stroke is referred to the end of the beat-stroke and becomes a part of the limiting sensation. There are other familiar phenomena which indicate that this reference of a stimulus occurring during the beat-stroke to the limiting sensation at the end of the stroke is a universal tendency. In jerking a bellrope, or tapping a gong with the foot, the tension of the cord and the impact of the foot on the lever seem a part of the common limiting sensation which includes the sound; in striking a piano or typewriter key the pressure sensation at the impact with the key is not distinguished from the resistance at the bottom of the stroke; in fact, the feeling of impact and the sound seem all to occur at the bottom of the stroke, although it often happens that the first impact occurs at or before the middle of the beat-stroke of the finger (or hand). Both subjects of Table III. succeeded in grouping the clicks into satisfactory trochees without a definite displacement. In the one case recorded of $\mathrm{Bg}$., where the trochaic grouping shows displacement, the sound precedes the limiting sensation of the hand at the accent, and the whole process seems to be reversed.

\section{2uestion as to the Priority of the Different Unit-groups.}

A number of discussions have centered round the question as to which unit-group occurs first historically. ${ }^{1}$

When one considers that all the types of groupings were developed in various acts long before the sense of rhythm appears, the unit-group can hardly be said to have a development. The particular type of grouping which first becomes coördinated and produces the rhythm-experience probably depends on chance and varies with the individual. The ordering of the unit-groups into larger unities is possibly a matter of historical development, and might be studied in primitive art-works.

\section{Groupings Larger than the Unit-group.}

It is doubtful if the normal unit-group ever occurs when it is not part of a larger whole. By experiment it has been shown

${ }^{1}$ Cf. Riemann, H. Musiklerikon, 94, where the three-group (dactyl) is derived from the two-group (trochee). p. 536 .

Squire, Mrs. C. R., 'A Genetic Stady of Rhythm,' Am. J. Psy., 'o, 12, 
that the coördination of the rhythmic movement is not perfect until two or three groups have been produced. ${ }^{1}$

It is very hard to produce a series of unit-groups without falling into some larger grouping. In poetry the simplest combination of unit-groups is the verse, or in the case of long verses, the verse-section. It is uncertain, however, if the verse-section differs from the verse; probably the verse divided into two sections is but the combination of two separate verses. Verses, again, are combined into stanzas, and stanzas occasionally become parts of a poem with a definite form as a whole. In music, the phrase corresponds roughly to the verse, and the period (strain) to the stanza; the movement made up of periods is the analog of the poem with a form as a whole.

The most obvious characteristic of the phrase-as it will be convenient to call the larger unity of the type of the verse-is the number of accents or unit-groups which occur in it. This is the basis of the ordinary classification of poetic verses and the classification of musical phrases by the number of measures they contain results in the same thing. A second characteristic is the pause which occurs in most cases at the end of the phrase. The end of the phrase is also marked by certain anticipative and recurrent factors like rhymes, refrains, and related pitch intervals and harmonies in music. One of the most important characteristics, though not inoicated by the ordinary notation, is the dynamic form of the phrase. The phrase rises to some one loudest, or most intense point which is the climax, and then dies away to the end.2

The process which gives rise to the phrase-unity differs essentially from the process which gives rise to the unit-group. The attempt to make the unit-groups subordinate to one unitgroup, as the short elements are subordinate to the accented element in the unit-group, or to build a new 'rhythm' out of the phrase-pauses or other recurrent factors overlooks important characteristics of the phrase. The recurrent factors are quite too far apart to come within the minimal interval for rhythmiza-

'Rhythm and Rhyme, loc. cit., pp. 421 snd 455.

'Cf. Wallin, Loc. cit., p. 136, 'Rhythm and Rhyme,' loc. cit., 446-7 and $455-6(5)$. 
tion. ${ }^{3}$ Moreover, each phrase is separated by a pause of indefinite length which is not a function of any of the duration values of the unit-group. Two beats alone of a single-beat rhythm could not give a satisfactory sense of rhythm, and yet the couplet is a satisfactory form of stanza.

There are many reasons for considering the phrase as simply the form of a single act, a movement composed of several subordinate movements. The tensions of the muscle-sets do not cease until the end of the phrase. The dynamic form of the phrase is the form of a movement; there is a rise to the central point of effort and then a decline at the end. Any elaborate, rapid flourish made with a pencil, or with a finger in the air, will show just such dynamic variations. When producing actual rhythmic phrases, it is easy to beat them as one complex movement; starting at an elevated point with the baton, one may beat a series of unit-groups which form a phrase as the arm descends, and it is with a feeling that the movement is done, and that the arm may relax, that one reaches the end of the phrase. In reciting verse, or in singing, a phrase becomes a single act of expiration; indeed, just this movement of breathing is probably the origin of musical phrasing.

If there is a pause during the phrase, within or between the unit-groups, there is always a feeling of tension of which the subject becomes quite conscious if the pause is prolonged, ${ }^{2}$ but at the end of the phrase, there is a release of these tensions, as if the coördination of the muscle-sets were at an end. In records of scanned nonsense syllables this dying out of the tensions at the end of the phrase is very striking. Every final syllable of the phrase ends in a long decrescendo, showing that the tension of the expiratory muscles dies out gradually at that point. The phrase pause is indefinite and non-rhythmical because it is simply the time necessary for the movement to die out. ${ }^{3}$

The way in which the phrase is brought to a close is of interest, because it is evident from experiments that the form of the coördinated movement of the phrase may be so indefinite

${ }^{3}$ Cf. Wallin, loc. cit., p. 72.

' 'Rhythm and Rhyme,' loc. cit., 421.

-Ibid., p. 447.

IIbid., p. 419. 
that it is not determined until the end of the phrase; and in establishing the coördination when one listens to a new phrase, it is evident that the form is not determined until the close of the phrase. A mere pause during which the tensions die out gives the movement a somewhat indefinite character, and very frequently the last elements of the phrase, or of the larger unities, are varied so as to make the end definite. The sense of finality is often produced by a heavy accent. This accent is often determined by some qualitative factor which attracts attention and receives emphasis. The heavy accent for finality, with a long dynamic preparation is especially noticeable in musical forms, and in some poems which 'end with a climax.' In the striking of any blow, the event, the point of the whole movement, is connected with the resisted momentum at the impact. The heavy impact at the close seems not only to mark the event, but to release quickly all the tensions of the movement; all the tensions of the movement seem to culminate in this effort and then disappear. It may be that the heavy blow upsets the coördination; it may be that the remaining energy of the process is all consumed in the final effort; it may be that there is some reflex connection between heavy contraction and relaxation.

When it comes to unities larger than that of the phrase, the movement theory can give no help. It is apparent that the connection of verses in stanzas, or of phrases in periods is unlike the connection of unit-groups in the phrase, and that the unity of the stanza is not the unity of a single movement. Each phrase produces a total impression, a 'Gestaltsqualität,' which appears only at the end of the phrase. It is a memory image of the ' motor' type, often associated with the appearance of the material on the page. Somehow this set of strains, this memory image, becomes to some extent the cue of the movement of the following phrases and may modify their character. Rhyme, and melodic and harmonic relations play an important part in this Gestaltsqualität. But as for the actual connection of the phrases, and the unity of the period, one can anly say vaguely that somehow the effect of the phrases is carried over, and a set of strains aroused which are satisfied by the subsequent phrases, and the conditions of this satisfaction are the conditions of the 
period form. One may imagine that the process is not unlike any process of obtaining an æsthetic unity, as in the composition of a picture, or the structure of a drama.

\section{The Rhythm of Verse and of Prose.}

There is no reason for assuming that the nature of the unitgroup of verse differs from that of other rhythms. Some of the recent laboratory work dealing with verse rhythm has been based on the conception of the unit-group as centering about a 'point' determined by three factors, force (loudness), length, and (relative) pitch.'

A motor theory involves the association of force and length; and pitch, to be sure, is physiologically a matter of muscular tension. But it is not therefore a factor in the movement-cycle of the unit-group. In the first place, Scripture's conception of the function of pitch is based on a mere logical analysis of the properties of an uttered sound. The sound has amplitude, duration, and pitch, therefore the ' centroid' will be determined by these factors. Quite as good a case can be made for quality ; changes of pitch frequently occur on accents, so do certain types of quality which have a demonstrable part in the rhythmization of verse, such as alliteration, assonance and especially rhyme. But whether either quality or pitch is a factor in the unit-group must depend on the nature of the movement-cycle, not on the occasional association of these phenomena with the unit-group. Pitch is due to the tension of the muscles of the vocal cords, and the tension appears in consciousness, but the muscles of the vocal cords are not capable of the reciprocal movement, with the sudden blow, necessary to muscles which take part in the rhythm-cycle. If the vocal cords participated in the blow of the rhythmic beat-stroke, the oscillation of the pitch during the enunciation of an accented syllable would be extremely wide, instead of being as a rule very slight. And there could never be a falling of the pitch on the accent, as the advocates of the pitch factor seem to assume. The voluntary tension of the vocal cords seems to remain about the

1 The 'centroid,' Scripture, E. W., ' Researches in Experimental Phonetics,' Stud. Yale Psy. Lab., 99, 7, p. ror: Wallin, J. E. W., loc. cit., p. 9. 
same during the utterance of an accented syllable, and in singing this evenness of pitch is a requisite. There is a mechanical reason for a slight change of pitch during the utterance of an emphasized syllable; the increased pressure of air against the vocal cords must increase their tension and tend to cause a slight involuntary rise and fall of pitch during the syllable.

If pitch were a possible constituent of the unit-group, we should certainly expect to find it in use in music, especially in vocal music always so closely associated with poetry. But in spite of the pitch material at hand, it is never used as a means of accentuation in the mere unit-group in any form of music, nor does music show any hint of compensating for an accentual effect of pitch. The same intervals are used in close succession on accented and unaccented elements, and the possibility of an influence on the mere grammatical accent has never even occurred to the musical theorists. In much the same fashion as in music there are melodies of speech, with intervals which are handled quite independently of the unit-groups, and which are never determined by them.

Length and intensity (loudness) figure in verse rhythm as they do in any rhythm. Intensity is the fundamental property of accent and marks the definite event in the movement-cycle. Since the movement-cycle is a cycle, and each unit-group though it may differ in details, must seem like the preceding group, there are certain temporal relations which can vary only within limits. As to individual syllables, Gurney is quite right in asserting that the accented syllable is longer because it is uttered with more force (i, e., with a movement of greater amplitude and involving more muscles). All verse is therefore quantitative, and all verse is accented. The distinction between classical and modern verse based on quantity vs. accent is a mistake. Recent laboratory work has shown that quantity is a characteristic of the syllables of ordinary speech and of a single syllable repeated rhythmically. ${ }^{1}$ And mere quantity without accents cannot constitute a rhythm. The quantitative theory of pronouncing Latin, advocated by Hale and others, is in a peculiarly unfortunate case, as it is wedded to a ratio of

'Wallin, loc. cit., p. 32. 'Rhythm and Rhyme,' loc. cit., p. 443. 
I : 2 between short and long, and that particular time relation is a hard one to maintain, even with the assistance of rhythm. As to the exactness of the time values of the classic poetry, everything depends on the character of its reading. If it was read, as is possible, as a musical rhythm, i.e., as a combined, not as a single rhythm, then as exact temporal relations as in music may have been maintained. That the ancients did not chant their poetry with a silent or visible accompaniment cannot be categorically denied. Such an accompaniment would furnish the secondary series of a combined rhythm. But such a combined rhythm in reciting poetry seems very improbable for it would hamper any attempt at expressiveness. It is useless to appeal to the 'delicate rhythmic sense of the ancients,' and assume that they got on without such an accompanying rhythm. The rhythmic training of the modern musician is indefinitely better and broader owing to the modern development of musical rhythm, and yet he cannot get on without the secondary rhythm; he has always to ' keep time.' The familiar dactylic hexameter is a good illustration of what the quantitative theory involves. The foot is supposed to have the form $|d \mathcal{N}|$ or $|d| d$ and it is usually explicitly stated that it is to be given in two-four time. The two-four form $\mid d \delta N$ is not a simple rhythmic group, and can be given only with an accompanying takt-rhythm, thus : $\left|\begin{array}{ll}\delta & \delta\end{array}\right|$. Such a beating of time, two beats to each foot, would have made the delivery exceedingly labored, whether the verse was read ' as in singing' or not, and it is beyond belief that any poet ever recited his verse in such a fashion. The reference to singing in support of the quantitative theory does not help, for accent is as necessary in singing as in any other type of rhythm. In the free delivery of speech, even in singing, a secondary rhythm is not present. Everyone knows that in recitativo singing, the time is not kept, $i$. e., one does not beat the secondary accompaniment. It is very doubtful if the utterance of the Greek bard was more rigid than that of the singer of recitative in the modern oratorio.

'Greenough and Kittredge, 'Virgil's Ein. and Bucolics,' '99, p. xxrvii. 
It is worth pointing out as against the duration-loudnesspitch theory of the unit-group of speech, that mere duration is not a factor of intensity or of vividness. The long duration that seems significant is the duration of an accentual movement and nothing else. A lag introduced into a verse just after an accented or unaccented syllable does not increase the intensity of the syllable preceding, whether the sound of the syllable is prolonged throughout the lag or not. A special case, in which the lag will increase the intensity of the following syllable is significant. During the lag the movement of the back stroke tends to continue, and at first seems to lift the apparatus higher, and thus gives a longer, more intense stroke to the next beat. If the lag continues past this point, the tension seems to die out, and the next beat is less intense than normal." And in music the prolonged note is not therefore an emphatic note.

Loudness is a factor in the accent of verse rhythm, because in reciting poetry the loudness represents the intensity of the movement. When we listen to verse, the more intense sounds rouse a greater motor reaction, because of the reflex between the ear and the muscular system, and because speech usually calls up a response in our own vocal organs. When one reads verse silently, the movements are probably movements of incipient articulation in the vocal apparatus. No succession of images which are not accompanied by actual movements can give rise to a rhythm.

The poet finds his material ready-made; his rhythms are mosaics of bits of movement already stereotyped in speech. Each word has the structure of a unit-group or collection of unit-groups with the consequent relations of accent and time. But the words of ordinary speech are not coordinated into a rhythm. The bits for the mosaic must be selected so that a regular pattern results, so that the movements will have the regularity and the form of a series of unit-groups.

An analysis of the movements of ordinary accentual speech will show the material of the unit-group of verse.

In the vocal apparatus the musculature of the cords contributes tensions, but does not enter into the movement-cycle. Move-

1 'Rhythm and Rhyme,' loc. cit., p. 427. 
ments with a rapid stroke are possible to the lips, jaw, tongue, palate and to the diaphragm in coördination with the abdominal muscles; and possibly to the chest-walls in coördination with the diaphragm and abdominal muscles. The movement cycle of the muscles of speech differs slightly from that of the limbs. In most cases the positive muscle sets contract and tensions rise, some time before the sudden release which makes the beatstroke. The action is much like that of snapping the fingers, when the contraction of the positive muscle-set occurs at first with middle finger and thumb pressed against each other and acting in opposition; when the release comes the beat-stroke has a much higher velocity than otherwise possible, though the length of stroke is still under control. In speech the air is confined in the lungs until the contraction of the abdominal muscles (et al.) has produced the tension, then the outlet is opened and the beat-stroke occurs. The vowel at the beginning of which the beat-stroke occurs has an 'explosive' quality. At the end of the beat-stroke, either the sudden contraction of the diaphragm (et al.) acts as the negative muscle-set and checks the ballistic movement, or the closing of the air passages by the next consonantal movement produces the negative resistance. The movements of consonants preceding vowels often serve to close the air-passages and raise the tension just before the beatstroke. Where the consonant is not vocalized, as $k, t, f$ and $p$, the closure is complete and the release is very sudden and the beat-stroke takes place at the consonant. Where the consonant is slightly vocalized, as $g, d, n, m, b, v$, the beat-stroke occurs in slow speech slightly after the beginning of the consonant. In the case of liquids and aspirates there is no preliminary rise of tension; the beat-stroke occurs at the beginning of the consonant, and the sound of the consonant continues into the vowel. When consonants follow the vowel, the impact of the consonant occurs at the end of the beat-stroke; it sometimes happens that the position of the beat-stroke (the expiratory pulse) determines the grouping of consonants otherwise alike. 'This train' and 'this strain' are distinguished in ordinary speech by the fact that in the word ' train' the beat-stroke cotnes on the ' $t$.' In the word 'strain' on the 'st.' In the case of a consonant pre- 
ceding a vowel, if the impact is not prolonged, the consonant seems a part of the beat-stroke. If the vowel is very brief, the consonant following the vowel may appear at the close of the beat-stroke of which it becomes a part; otherwise it will occur

DIAGRAM OF BEAT STROKES IN SYLLABLES WITH CONSONANT:
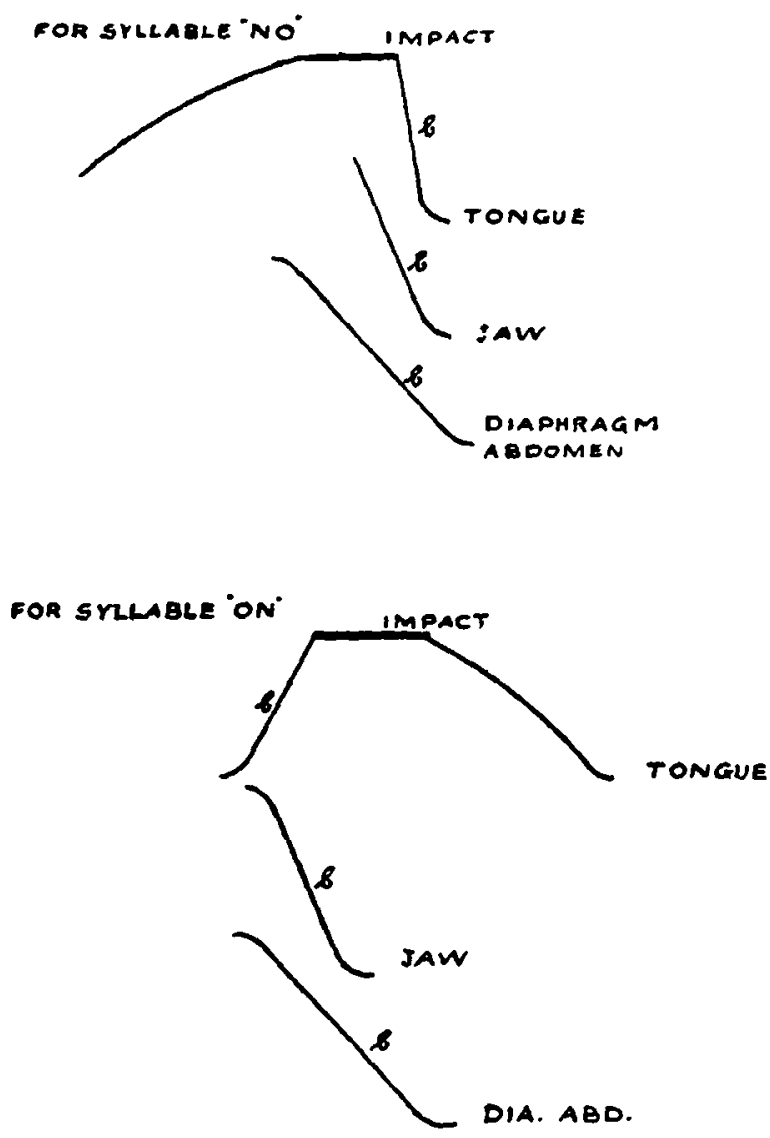

FIG. 7.

in the relaxation period. For the various relations of the consonants and vowels, compare the accompanying diagram, Fig. 7 .

In ordinary speech, the length of the staccato vowel is the length of the beat-stroke. It is possible, however, for a residual tension of the positive muscle-set to maintain the tone during the relaxation phase, until obstructed by the next consonantal 
snovement. (This residual tension may be nothing more than the mechanical recoil of the respiratory muscles.)

The material of the unit-groups has much to do with their effect in verse. Alliteration and assonance give the unit-groups identical movements, and serve to make the rhythm more regular and more exactly coördinated. Their effect on the verse, then, is more than merely 'qualitative'; they directly affect the rhythm.

In the determination of the larger unities, the verses and the stanzas, there are a number of important factors which must not be overlooked. Each verse has a dynamic form, and its coördination with other verses is dependent on this dynamic form, which is simply the form of the phrase-movement. In the same way there are pitch relations which may give the verses a good or bad melodic relation. Dynamic and melodic relations enter into the phrasing of verse quite as really and quite as definitely as they do into musical phrasing, and much of the beauty of verse depends on these factors.

In rhyme, the relations of pitch are limited, if the rhyme is to be heard.' The rhyme determines a dynamic form with the climax at the rhyme, but it makes the verse-pause optional. Very elaborate and definite stanza structures are possible with the aid of rhyme, and almost all the modern stanza forms are dependent on it. Without rhyme the dynamic form of the verse is variable, but a pause at the end of the verse is an essential, if the verse is to stand as a phrase. ${ }^{2}$

It is evident that the rhyme functions as one of the factors in coördinating phrases, but the nature of the rhyme impression is an enigma. The beat-stroke must be the same, but the consonant at the beginning of the beat-stroke must be different; an identical beat-stroke with different consonants at the end of the stroke is not rhyme; a vowel without a consonant will rhyme with one preceded by a consonant. The best one can say is that the rhyme impression is somehow dependent on the manner of initiating the beat-stroke.

Dynamic and melodic relations of the verse are often deter-

1 'Rhythm and Rhyme,' loc. cit., p. 430.

Ibid., 449 and 464 . 
mined by the meaning of the verse, but this does not mean that the 'content' is a factor in the rhythm. Many variants of a given rhythm are possible. Which one of these forms is chosen may be determined by the 'content,' but each one must be rhythmic in itself. The fact is that in selecting his material for a verse or stanza the poet must find material which in all its aspects will fit into the pattern of his rhythm. He cannot put a certain rhythm and a certain 'content' together and hope for a composite effect in which a 'logical coördination' plays a part in the rhythm. Any rhythm is a rhythm independent of any meaning its material may convey. It must.remain a rhythm with all the lags, pauses and variations that serve the purpose of making the meaning clear, when it is stripped of all meaning. The rhythm of a foreign language is in nowise dependent on the meaning of the language.

Although the words of ordinary speech show the grouping of the unit-group, the groups do not occur regularly enough so that a coördinated movement from group to group is established. In the sense of having regular unit-groups, no prose can be said to be rhythmic. The rhythm of prose is only a matter of the coördination of the phrases into larger wholes. The general movement of each clause or sentence in prose is similar to the movement as a whole of the rhythmic phrase, and like the rhythmic phrases, these clauses or phrases can be grouped together. The songs of birds and animal calls and well-written prose may all have phrases grouped into periods, and to that extent may be said to be rhythmic; but the regular succession of unit-groups is not present.

The most elaborate investigation of speech rhythms published is that of Wallin. ${ }^{1}$ The material used was the fully developed art-work. While one may not agree with the theories advanced, the work is suggestive, and many interesting things appear. The method, however, necessarily limits the fruitfulness of the investigation in some directions. The statistical study of the poem, a complex art-form, is valuable for description, but can seldom furnish material for explanation. There is need of painstaking work with artificially simplified material

1 Loc. cit. 
to determine some of the most important principles of the single rhythm in verse. We do not know the conditions for the substitution of one rhythmic group for another which occurs so often in modern verse. There is little known of the characteristics and conditions of the movement of the verse as a whole, and there is nothing known of the larger unity of the period. The recording of verse rhythms for study presents many diffculties. If possible, the measurements should be visual. The method used by Wallin of determining the limits of syllables by sound is open to error both because of the continuous confusing noise which the stylus of the phonograph makes in rubbing against the record and because of the personal equation. Judgments of sound intensity based on hearing are of little worth. Subjective accentuation plays too large a part in such judgments. A record capable of reproduction and at the same time of visual measurement should be the best, and the microscopic method of study is certainly superior to mechanical enlargement, if error is to be avoided. But at best any record at present possible involves the use of a diaphragm, and the resonance of a diaphragm is always a source of error. Visual measurements of amplitude can only be made with identical vowels, as every vowel has its own amplitude of vibration. Pitch relations play a part in the phrasing of verse, but phonographic records of pitch are not reliable and are peculiarly tedious to study. For an accurate study of the conditions of verse rhythm, material adapted as far as possible to the limitations of the phonographic method must be used.

\section{Combined Rhythms.}

Music with its elaborate and complex figures and its developed notation is the field of combined rhythms. The simplest types of combined rhythms are the simple measures $2|j| j$,

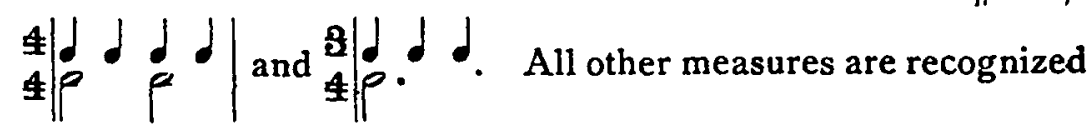
as a development of these forms, and most theorists derive the four-four measure from the two-four and consider the double and 
triple divisions alone the basis of music ; the unquestioned twofour character of the six-eight measure and the sporadic or even doubtful existence of the five-four make this seem probable. The more complex measures are built up by making a group represent a single division of the two-four or three-four measures.

The dynamic properties of these measures are well known. Accent on the first beat in the two-four measure; accent on the first, and a secondary accent on the third in the four-four measure; and accent on the first with a possible secondary accent on the third in the three-four measure; these are the familiar dynamic forms.

\section{r. Nature of the Measure.}

It should hardly be necessary to point out the essential differences between this new type of unity and the unit-groups of the single rhythm. Nevertheless they are often confused. The unit-groups are composed of beats having striking differences of accentuation, and wide variations in the length of the intervais, and in all the normal forms (except the singlebeat and the tremolo) the intervals are essentially uneven ( $c f$. fig. 3, p. 272). The measure on the other hand, has but slight differences of accentuation, the time values vary little, and the intervals are practically equal. Most fundamental difference of all, the measure is alzways composed of unit-groups. Since the measure only appears when rhythms are combined, its raison d'être must be in the movements of the combined rhythms. Although the movement-cycles of combined rhythms must be distinct and comparatively independent (as distinguished from the action of the major and minor muscle-sets in the single rhythm) the processes must influence each other, however slightly, if they are simultaneous; and one might hope to find in the primary series of a combined rhythm some traces of the movement which makes the measure unity. In records of rhythm, the factor which shows slight influences the most readily is the length of the beat-stroke. In Table $\mathrm{V}$. averages are shown of the length of the beat-strokes in the beating of simple measures. In every case the lengths of the beat-strokes show a gradation in the case of a measure, a gradation in keeping with the observed accentual relations within the measure. Such 
TABLE V.

RELATIVE LENGTHS OF THE BEAT-STROKRS IN VARIOUS STMPLE MEASURES. Actual strokes 4-6 times (mm.), the values given. Beating with a Baton.

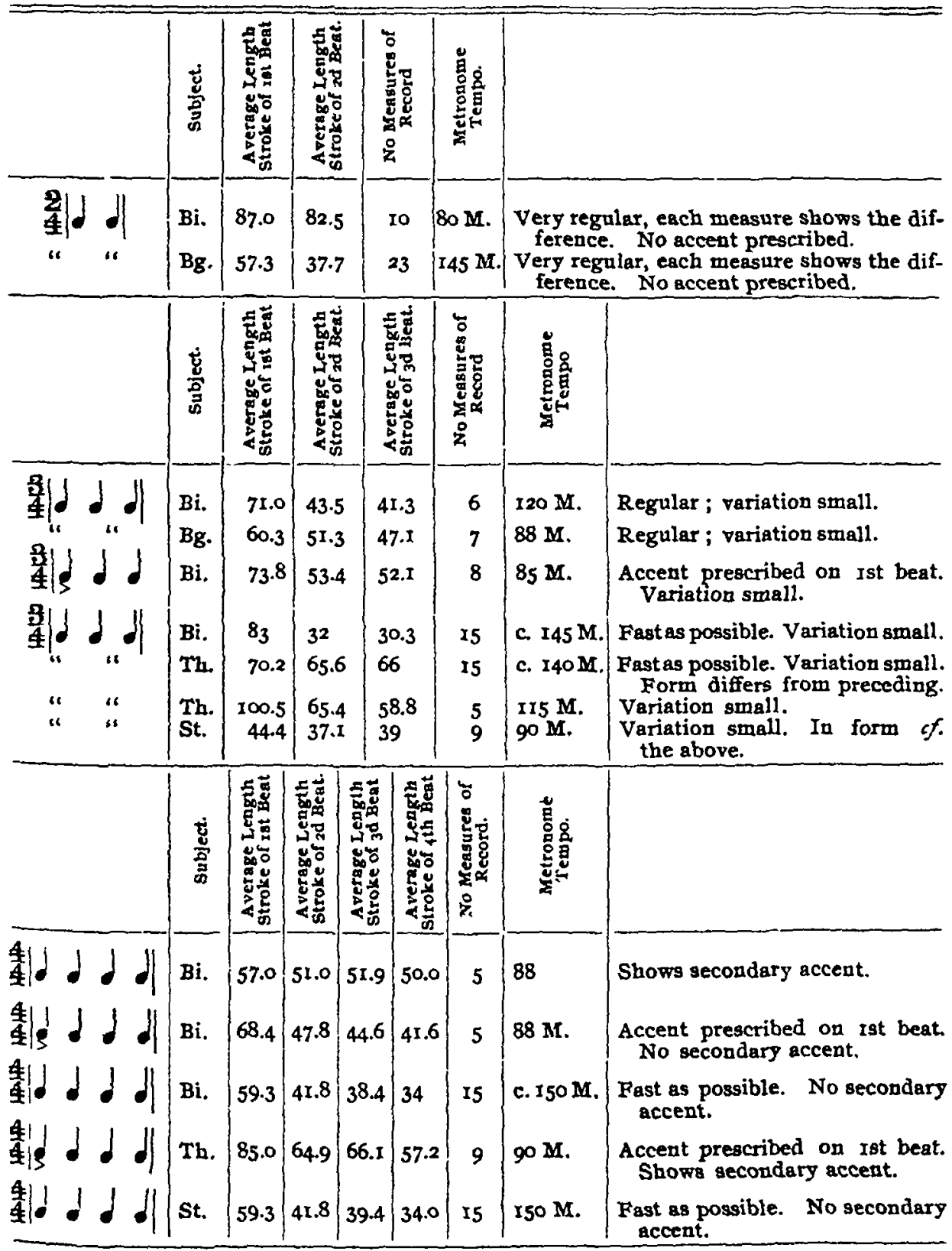


regular dynamic variations must be due to a movement, and in certain cases this movement may become apparent on the kymograph record, as in cases where the upper limit rises higher and higher or sinks lower and lower at each beat throughout the measure showing that the measure is among other things a slow upward or downward movement.

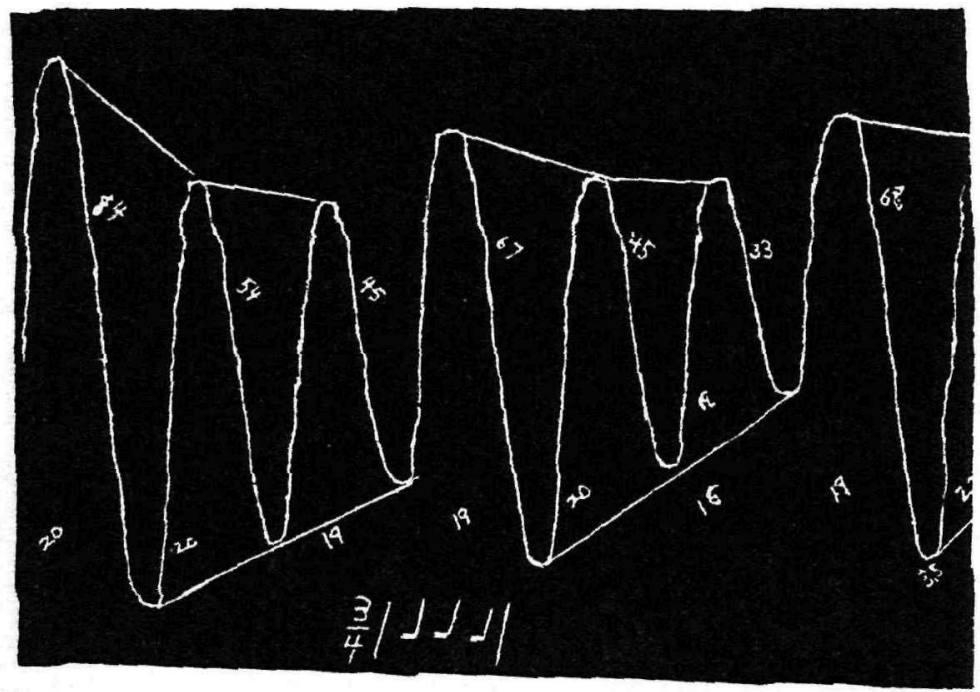

FIG. 8.

Lines have been drawn connecting the curves to show the general form of the movement.

The measure must be due to a secondary movement-cycle simultaneous but comparatively independent. The simplest possible measures may be figured as in Fig. 9. Four-four must be

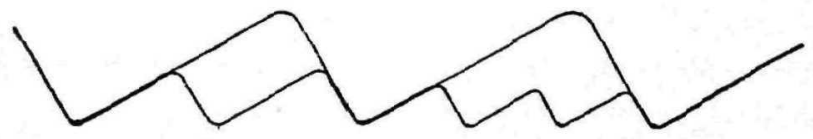

FIG. 9.

considered a compound two-four measure if it has a secondary accent, as it has at ordinary tempos. The limits of the length of measure must be due to the temporal conditions of this secondary movement. The ordinary unit-group (single-beat or complex 
group) does not show wide variations in duration. Miss Hallock asserts in a recent paper ${ }^{1}$ that an analysis of the standard editions of Beethoven's sonatas shows an extreme range of $60-80$ as the metronomic marking of the unit-group; the average marking for all the sonatas is 64.4.M. Well-known conductors gave $64 \rightarrow 72 \mathrm{M}$. as the takt usually used in their conducting. (The pulse to which this author refers the rate established can have nothing to do, of course, with the length of the unit group.) It may very well be that the multiple of this value (a little less than I sec.) by three or four represents the maximal interval for the slower, automatic, regular movement which produces the measure.

When the measures take on elaborate forms, the rhythm of the melody or cantus firmus has the unit-groups of the types previously discussed (iamb, trochee, dactyl, tremolo, etc.). The processes in music are usually very regular, but the unit-groups often show the irregularity due to their process of production. The trochee may be of the form $\sqrt{2}$, but when heavily ac-

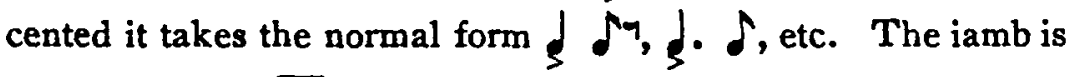
written 7. ( $/ .3$ is a false convention) but its values when executed nearly always approximate those of the normal iamb with the short element much nearer the long than the notation indicates. This cantus-firmus rhythm is the more mobile, living process of the combined rhythm; it has the type of movement of the single rhythm, and probably the same coopperation of amalgamating minor and major muscle-sets in the unitgroup. It is quite possible in forms like the canon and fugue to have two such cantus-firmus rhythms running simultaneously but not in unison. In such a case it is significant that there must be a very definite takt-keeping to prevent the process falling into chaos. This takt-keeping represents a series which must be present in every combined rhythm.

2. Characteristics of Combined Rhythms. Effect of Changes of Tempo on the Character of a Rhythm. - It is a familiar fact that a decided change of tempo changes completely the char-

'Hellock, Miss M., 'Pulse and Rhythm,' Popular Science Monthly, 'o3, 63, September, 425 . 
acter of a musical rhythm. A waltz may become a hymn and a mæstoso processional a two-step by simply altering the rate of execution. Such changes are only noticed in music, and therefore the combination of rhythms probably has something to do with the change. On examination the change turns out to be more than a mere variation in rate. In the first place, new measure movements may appear; what had previously been three-eight may become six-eight; two-four measures may be combined to form four-four measures with secondary accent. At the same time, the takt-rhythm changes, the beats occurring less frequently as measured by the beats of the other rhythms. As already noted, the takt of music does not vary greatly in different types; it tends to remain at about the same absolute rate. Consequently, if the rhythm is played rapidly, a larger number of beats of the primary rhythm will occur during a single interval of the takt-beat. This change will affect the grouping of the primary rhythm, making trochees where before were single-beats, tremolo forms where before were trochees, etc. All these changes are radical, for they affect the grouping, and that means the form of the movements of the rhythm. The phenomenon emphasizes the fact that not temporal relations but the movements involved are the fundamental things.

In combined rhythms the temporal irregularity is very slight. An accented note is known to be longer in general than an unaccented, and at the end of the measure there may be a slight 'pause' prolonging the last beat of the measure.' But these variations are small and the ordinary mathematical notation of music is quite justified. How the combination of rhythms leads to such regularity is the question. In the first place, one must suppose that the movement-cycle of each beat is practically identical with the movement-cycle of its neighbors in the same series. In the figures of the simple rhythms there are beats made by a part only of the muscle sets, but in each combined rhythm there must be at least one rhythmic series in which just the same muscle-sets take part in a movement of just the same amplitude at every beat. At least one series must 'keep time,'

${ }^{2}$ Christiani, A. W., Principles of Pianoforte Expression, N. Y., '85. Riemann, H., Dymamik und Agogik, Hamburg, '84. 
and there is but one way in the human organism to keep time, and that is to set a reciprocating movement to repeating itself without change. To some extent the processes must check each other; if the primary rhythm is executing three movements against one of the secondary rhythm, as in the form

D. $\partial \partial$ it is evident that the primary process will serve as a guide to the secondary, and in return the secondary process will serve to keep the primary regulated, as the movements must go together and fit into each other ( $c f$. Fig. 9, above). An accent in either series will tend to prolong the series at that point, but if the other series is unaffected, its movements will serve as the stimulus to the movements of the first series and hasten the relaxation-process after the heavy contraction. As

\section{TABLE VI.}

THE INFLURNCE OF ACCENTOATION.

Effect of the two processes on each other and effect of the accent on the temporal relations.

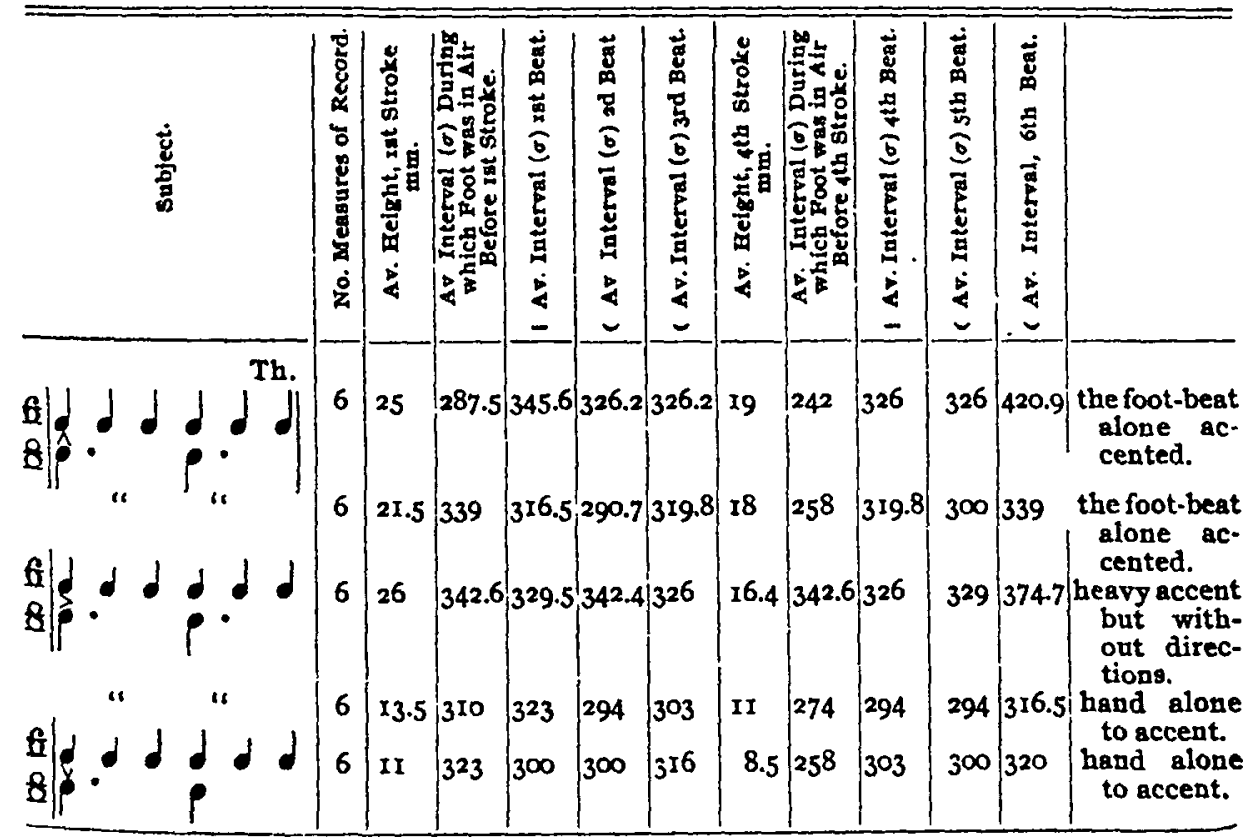

Records show that foot always has accent. 


\section{TABLE VII.}

Cashs Wherg the Reythy of the haNd Phrturbs tha Rhytha of TEI Foor.

Ta. In every case where the foot is raised before the $\smile$ of $\_\smile$ and $\checkmark-$, the foot movement is perturbed. 15 cases.

Sn. In 5 cases in II where the foot rises before $\backsim$ of $\backsim-$ the foot movement is perturbed. 5 cases in $I r$.

Th. In the form $\sqrt{8}$ and its movement is perturbed. 7 cases in the 9 measures.

Bg. In the form

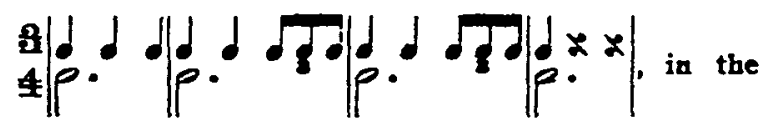
measures with the figure $N_{y} d$ the foot movement is perturbed. ro cases.

Bg. In the form $\frac{\mathfrak{z} \mid \mathrm{f} \text {. }}{4}$. the foot movement is perturbed by the figure $\int 2$ cases in the 9 measures.

Bg. In the form $4 \mid d \downarrow d$ the foot rises at the second tap of hand, and the movement of the foot is perturbed at the third tap. 4 cases in 8 measures.

Bg. Trochaic form, $J=120 \mathrm{M}$., the foot rises almost immediately after its descent, but shows perturbation at the - of the hand. I3 cases in 17 .

the movements are uniform (z.e., there is no amalgamation of muscle-sets at the accent, save in the melody series) the only difference between the accented and unaccented beats may be in the length of stroke which will cause but a slight variation in the process.

Although different movement processes may be executed side by side, perfect independence is not possible. Even in the case of movements which are outside the rhythm-apparatus, as in turning pages or talking while playing at the piano, an influence is noticed. It often happens that one rhythmic series is accented without the intention to accent the concomitant series. The influence of accentuation in such conditions, on the other rhythm, was studied in some detail in the case of one subject. Table VI. shows that with this subject accentuation is associated 
with an increase of length of stroke, and that the foot or hand rises later after the accented stroke ( $c f$. Fig. 4, p. 273). The interval both before and after the accented stroke is longer. Both processes show the accent, whatever is prescribed.

In some cases a movement not only affects another movement, but causes an actual disturbance. In Table VII. a list of such 'perturbations' are given.

They all occur during the back-stroke. They are all cases in which the primary rhythm affects the slower secondary rhythm. In every case the contraction of the muscles of the primary rhythms seems to have acted as a stimulus to the negative muscle-set of the secondary rhythm, causing a sudden deflection in the negative direction. Féré mentions cases in which rhythmical movements perturb each other.

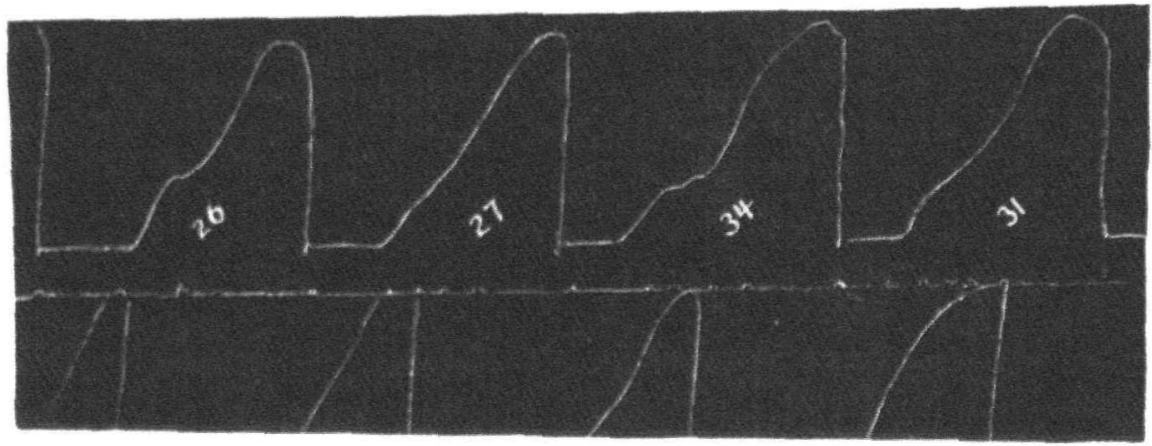

PIG. Io.

The exact relations of the superposed movements differ in different subjects. With a primary and secondary rhythm, four of the subjects, Bg., Sn., M., H., raise the foot as a rule almost immediately after the beat-stroke at all tempos; the foot is in the air throughout the whole relaxation-phase. Four other subjects, Th., Bi., Ta., St., do not raise the foot until late in the relaxation-phase. At rapid tempos they revert to the previous type, and the foot is in the air throughout the relaxationphase.

'Pére, Sensation et Mouvement, ze éd, reviewed in Ztschr. f. Psy. u. Phys. d. S. Org., 'O3, 32, S. 421 . 
The records were inspected to determine at what point in the relaxation-phase the foot is raised in the case of Th., Bi., Ta., St. In some cases, e. $g$., Ta., it is evident that at times the foot is raised at random and remains poised until the beat-stroke. In many other cases the rise of the foot coincides with some subordinate tap of the hand, usually with the last one in the relaxation-phase. At times it seems to occur with the back-stroke of the hand before this last tap, and at other times with the backstroke of the hand following this last tap. There is reason to suppose that the movement of the foot is actually coördinated with this last tap, which serves, partially at least, as its movement-cue. It is probable that with many subjects the secondary rhythm is not actually produced in the muscles of the leg and foot. The secondary rhythm is probably beating in other muscles of the organism and the foot simply reacts on signal.

The two or more rhythms which combine appear in consciousness as one complex because there are certain coördinations, certain tensions which have to exist to support both processes. Just as in the single rhythm, the phrase is a movement which includes all the movements of the combined rhythms. In music there are other factors which make toward unity, but they are not essential to combined rhythms. All this presupposes a rather complex set of movements. But it is doubtful if any psychological motor scheme can surpass the actual complexity of the simplest reactions of the muscular apparatus.

\section{The Rhythm of Music.}

The striking difference between the rhythm of music and the rhythm of verse is due partly to the regularity and multiplicity of the rhythmic process, and partly to the character of the unit-groups in the individual rhythms. At first sight they present an indefinite variety of forms. Many of them turn out to be dactyls, trochees, and iambs in a variety of notations. But in addition there is a large use of single-beats, and of tremolo-groups of all rates. These tremolo-groups take the place of a single unit-group, or of an element in the unit-group, and thus add an indefinite variety to the compound forms of the unit-group. The use of tremolo and single-beat is possible 
because of the regularity of the process. The other rhythms carry on the process during the single-beats, and the regularity of the recurring takt makes it possible to fill in an interval with the tremolo. At the same time, the form of the movementcycle may be changed for various purposes. Since there is now one process at least to act as a cue to the primary rhythm, its movements may vary, and yet give the beat-stroke regularly. In staccato notes, the staccato implies a movement-cycle in which the back-stroke is made very rapidly and is followed by a long wait in the poised position before the next beat-stroke. The peculiar staccato before an accented note so often noticed in the phrasing of organ music ( $\hat{F} \mathcal{j}$, etc.) is very interesting. It makes apparent to the ear the unusual rise of the back-stroke for the long and therefore accented beat-stroke which follows. The device is especially important at the organ, as intensity of sound for grammatical accent is out of the question ( $c f . \mathrm{p} .283$ ). In the case of single-beats the note may be 'held' through the time of several unit-groups. The other series keep the whole process alive, and are a constant stimulus for the maintenance of the tensions of the note held, and the series in which it occurs does not lose its identity, unless the note lasts through an entire section or period (organ-point). ' Rests,' which imply that the muscles of one movement remain poised for an appreciable time, become possible while the other movements go on. Interest centers in the cantus-firmus rhythm, and the continuity and activity of that particular rhythmic process are usually provided for. Legato which insures a tension throughout the unitgroup is often used, and where legato is impossible as in instruments of percussion other devices are resorted to. It has already been pointed out that the tremolo type of figure has a peculiar continuity (p. 279). This continuity of the tremolo is often used to keep a melody alive and vivid. The early compositions written for the harpsichord and clavichord have a variety of tremolo figures in the melody; trills, turns, runs and all sorts of embellishments really superfluous to the true melodic notes. The same thing appears in the arrangements made for the street-piano whose melodies inust carry long distances and compete with street noises. 
It is a familiar fact that the melody is the most important voice, and that the time-keeping part comes next in importance. Usually the time-keeping part is the lowest part, probably because the lower tones stimulate larger, slower muscle-sets. The other parts for the average hearer or player often degenerate into mere harmonic factors, chords, and do not figure as true independent melodies unless some peculiarity brings them out.

As to the actual muscle sets at work in a musical rhythm it is hard to say. In many cases it seems doubtful if the muscles of the performer which actually produce the tones can be the source of the rhythm. So many non-rhythmical movements enter in - movements up and down the keyboard of piano and organ, from lever to lever in wind instruments, movements of the bow and up and down finger-board in violin. And the same muscles have to execute a large number of extraneous movements, such as turning pages, pressing pedals, pulling stops, etc. When a melody at the piano is played by the thumbs alternated as chance permits, it seems probable that the real rhythmic process of the melody is independent of the hands and that they are controlled by it. An independent process of takt-keeping is very common.

The phrases and periods of modern music are very clearly defined. Although elaborate phrases both with and without rhymes had been familiar in poetry, rhythmic periods with articulate parts were not developed in the history of musical form until harmony had reached a stage when the harmonic period was possible. ${ }^{1}$ The takt of the older contrapuntal music was used simply to regulate the ensemble. This shows how intimately the larger grouping of musical rhythms has been associated with harmonic and melodic relations. In modern music the phrasing is remarkably organic. In many periods the end of each section, and the end of each phrase, have definite harmonic relations which correlate them, and make it possible for the listener to say just what point has been reached in the process. The cadence at the end of the period is always an unequivocal indication of rhythmical finality. In the melody, also, the use of imitation in the figures and intervals, and the

'Parry, C. H. H., Evolution of the Art of Music, New York, 1896, p. 109. 
repetition of sections or phrases serve to articulate the rhythm.

The dynamic forms of the larger unities are not so definite, and there is often a choice of forms; but here, also, there is frequently a tendency to accentuate the phrasing.

It is characteristic of rhythm that many of the apparent irregularities of music should in reality be normal elements in the grouping. At the close of a phrase or period long notes are frequently shortened, and short notes are lengthened. In records of hymns, played by excellent musicians, made by Sears ${ }^{1}$ such variations show very clearly; some of the deviations from the mathematical intervals are very wide. At the end of the period, the general movement of the phrase comes to a close, and the tensions of at least a part of the processes die out before they begin again. The pause at the end of the phrase is for this purpose, and its length does not depend on the indicated interval, but on the requirement of the particular type of movement. In some cases (as in Lux Benigna, Dykes) one of the rhythms continues through the pause, and the finality process of the phrase must accomodate itself to the intervals of that rhythm. In mechanical devices, and in badly done ensemble playing, the takt is kept rigidly through every pause. Such a process does not contribute to the regularity of the rhythm, and in some cases may seriously disturb it.

Aside from such ' irregularities' which the rhythms require, there are various minor variations for the purpose of expression. These are not essential to the rhythm, neither do they disturb it in any way. Expression which disturbs the rhythm is false expression. A gradual increase or decrease of tempo (accelerando and ritardando) are very common. The hold on a single note usually marks a phrasing pause. A slight variation of the intervals of one rhythm without affecting the intervals of the secondary rhythm is a very effective device, and is the true rubato, rather than the utter failure to keep the time which goes by that name.

In considering the possible effect of 'content' on rhythmization, the song often shows a wide variety of rhythms for ap-

\footnotetext{
'Sears, C. H., 'A Contribation to the Psychology of Rhythm,' Am. J. Pรy., 13. p. 28.
} 
proximately the same content. Heine's ' $\mathrm{Du}$ Bist Wie Eine Blume' has its own effective rhythm, but it is not followed by the musical settings of either Rubenstein, Liszt, Schumann, or Cantor. Their rhythms are all different, yet all appropriate, and in a sense expressive.

The laboratory analysis of musical rhythm should be much more easy than that of verse rhythm. The pitch relations are definitely determined, and the manner of tone production permits a fairly accurate determination of intensities in at least one instrument of wide application, the piano. Registering apparatus for duration and intensity has been applied to some extent. Sears ${ }^{2}$ has published some satisfactory records of the temporal values of several compositions played at the organ and Binet and Courtier have studied ${ }^{2}$ the temporal and intensity values of several musical forms played on the piano, but the intensity of each separate note was not recorded, and the record is not satisfactory for the detailed study of rhythm. An efficient recording apparatus for the piano presents no serious difficulties. A careful study of the details of the variety of musical figures, of the many combinations such as , of syncopation, of ritardando and accelerando, and of the temporal and dynamic conditions of phrasing should yield valuable results for the general theory of rhythm. Changes of tempo offer an excellent method of studying the emotional effects of rhythm.

\section{The Central Processes of Rhythm and of Discrete Succession in General.}

The well-known action theory of Münsterberg sets forth the principle that the outgoing nerve currents have as much to do with the determination of a content of consciousness as the incoming currents. Vividness is the important attribute of the sensation which is determined by the outgoing currents. ${ }^{1}$ In view of the action-theory, there are two ways in which one may

1 Loc. cit.

' Binet, A., et Courtier, 'Récherches graphiques sur la musique,' $L$ ' $A n$. Psy., '96, pp. $201 \mathrm{Ef}$.

Münsterberg, H., Grundzüge der Psychologie, 'oo, Leipzig, S. 525 ff. 
picture the central processes involved in a motor theory of rhythm. The first way and the one founded on the ordinary view that contents in consciousness are the result of afferent currents, is to consider a rhythm as a series of kinæsthetic sensations from the various joints and muscles involved in the rhythmic movement. During the relaxation-phase there are sensations of changes of tension with the slow movement of the joint; during the contraction-phase there is first a rapid movement of the joint, followed by sudden, intense sensations of tension at the end of the beat-stroke. The grouping and connections are due to the connection of these kinæsthetic sensations, and the striking differences in vividness are due to the changes of intensity in the kinæsthetic sensations, especially of the muscular strains. Such an interpretation is very natural, but it involves difficulties when the rhythmization of other than kinæsthetic sensations is considered. Instead of referring the changes in a uniform sound series which we voluntarily rhythmize to a superposed kinæsthetic series, we speak of the sounds themselves as changed; they are now nearer together, 'grouped,' and their relative vividness (usually referred to a supposed change in intensity) has become different. All these properties of the rhythmized sound we refer to the sound sensations and to them alone. Indeed, there are some who would deny after a careful introspection that movements have anything to do, directly or indirectly, with the rhythmic perception of the sound series.

Instead of giving to kinæsthetic sensations the anomalous capacity of changing the vividness of other sensations of an entirely different order, it is far better to make the motor theory of rhythm an application of the action theory of Münsterberg to this particular field. Then the changes in vividness of the sounds are not due to the afferent kinæsthetic sensations of the accompanying movements, but to the efferent currents which produce the movement. The innervation of the musculature in the perception of a series of sounds leads to the observed changes in vividness. An essential factor then in a rhythmic series of kinæsthetic sensations is the series of efferent processes producing the rhythmic movement. 
A rhythm is a voluntary temporal succession with voluntary changes of vividness of sensory material. It should therefore present an excellent field for detailed and controlled experimentation on the 'time sense' and the process to which changes in vividness are due. There are already a number of observed facts of considerable theoretical interest. A rhythm as the one accurate measurement of time ; the phenomena of temporal displacement; the phenomena of subjective accentuation; the fact that at high rates of succession sensations appear in consciousness simultaneously; the fact that the limit of rapidity in hearing a series and of producing one by movements is approximately the same; the fact that in rapid succession certain sensations at regular intervals may not appear in consciousness though their intensity is the same as that of intervening sensations which are perceived; radical changes of a rhythm due to mere changes of tempo; the phenomena of temporal displacement in nearly simultaneous sensations of different orders; all these should throw some light on the problem of the perception of succession.

\section{r. Central Processes During the Movement-Cycle.}

During the back-stroke both the positive and negative muscle-sets are contracting under the continuous guidance of the kinæsthetic sensations which pour in from the moving parts. It is a 'regulated' movement; as Rieger puts it, one that does not happen more rapidly than the nervous changes in the muscles can take place. All of which means that during the backstroke there is a constant regulating flow of nerve currents from the movement-localization (sensory) centers to the efferent motor centers. And on that constant inflow of sensory currents, and outflow of regulating currents the sense of continuous change in the temporal localization series depends. But when the beatstroke begins all this is changed. No longer are both sets of muscles contracted, and no longer are they continually inhibited and stimulated by currents from the localization center. Instead, the negative set relaxes suddenly and the positive set contracts, then without any regulation from the localization center, the positive set relaxes, the limb is carried along by inertia for some 
sig. and then, still without any regulation, the negative set contracts automatically at the end of the beat-stroke. Then the tension of the negative set decreases, the positive set contracts slightly and the usual type of movement takes place during the the next back-stroke. It is evident that at the beginning of the beat-stroke the moter centers suddenly cut loose from the regulating localization centers and perform their function quite automatically until the close of the beat-stroke; the explosive reaction seems to be performed at the cue of an image of the movement, nothing more. The localization centers do not come into touch again with the movement until the end of the beatstroke. And all the sensations occurring during the movement seem to be telescoped as it were into the end of the movement. At that point they all seem to get their place in the localization series.

The vividness of the sensations occuring during the movement-cycle is independent of their objective intensity and depends on their position in the movement-cycle.

In imagining the central processes which the facts require, one must reason from crude mechanical analogies. But at bottom, the central processes must be mechanical and more elaborate and complicated than any possible construction. One of the striking facts about the rapid type of movement of the beat-stroke is that its rapidity is not increased by practice. There are variations among different parts of the body and among different subjects, but even the long training of piano playing covering an extended period of growth cannot alter the rapidity of the movement. ${ }^{1}$

As previously noted, the maximal number of movements per second possible to a limb depends on the duration of the beat-stroke. This definite and unchangeable interval of the beat-stroke points to a fixed type of mechanical arrangement between the motor centers governing the positive and negative muscle-sets. The coördination of muscles into negative and positive sets is very easily changed and readjusted, but while it persists, it represents some fixed type of mechanical connection. We may imagine that the centers of the positive and

'Reif, loc. cit. 
negative muscle-sets are arranged tandem, so that the efferent current must first cause the positive center to react, before it can overflow into the negative center; the time required to effect this serial stimulation is the duration of the beat-stroke. Or, since the action is really a double one in each center, because the muscle-set first contracts and then relaxes, we may imagine that the action is controlled by a mechanism vaguely like the cut-off mechanism of a reciprocating steam-engine.

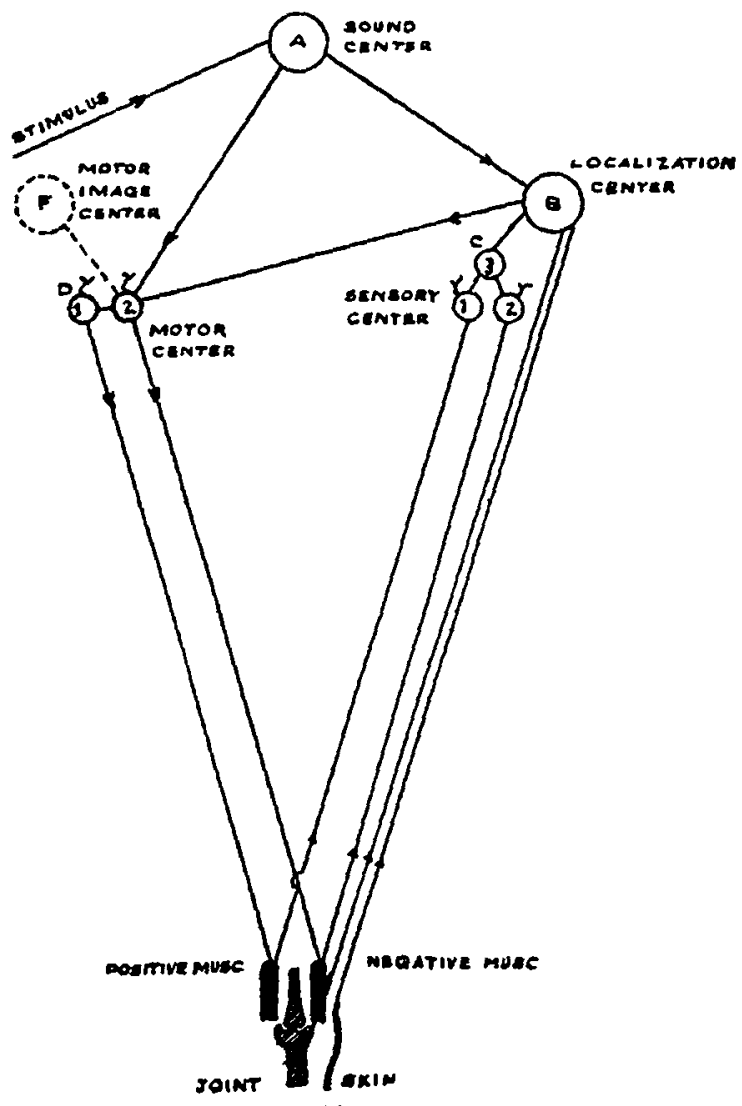

FIC. II.

As for the changing tensions between two contracting muscles which are essential to the sense of continuous change, one may suppose that the 'center' in which this sense of change is produced is always affected by a difference of tension, and has the 
same connection with the afferent centers for tension sensations from the two muscle-sets as has the galvanometer in the Wheatstone bridge. The whole process may be roughly figured as below, Fig. Ir.

$A$ represents the sound center from which a direct reflex runs to $B$ (I and 2), the motor center. $B$ is the localization center for the series of sensations during the movement-cycle; it receives stimulations from the joints and skin, and difference stimulations from $C, 3$ which stands in bridge relation to $I$ and 2 of $C$ which receive the afferent tension stimulations from the muscles. In the process of rhythmization a sound stimulus passes to $B$, where it gets its position in the time series, and at the same time the outflow from $A$ and $B$ to $D$ determine its vividness. During the time of equilibrium, just before each beat-stroke, the steady outflow from $B$ would give the sound a a slight vividness, and the inflow of currents to $B$ would make the sound continuous with the preceding sensations of the backstroke. If the center $B$ were connected with other localization centers, in which changes were taking place (as with a secondary rhythm), then the sound during the 'pause' would find a place in the other series. But at the beginning of the beat-stroke the connection between the localization center $B$ and the motor center $D$ suddenly ceases. This inhibition is brought about perhaps by a difference stimulation-process (since the muscles are now in different phases, one contracting and the other relaxing), perhaps by sudden increase of tension in $D$ due to an inflow from the motor image center $E$ which makes it impossible for $B$ to discharge into $D$, and thereby preventing the incoming sensation from receiving any vividness till the tension of $D$ decreases. At the close of the stroke, the inhibition of the flow from the localization center $B$ to motor center $D$ is removed, and the normal condition of $B$ is restored. And now all the stimulations which are still alive in $C$ and $A$, or are on the way flow at once into $B$, and get their position in the time series en masse. Thus all the sensations which occur during the beat-stroke and persist to the end of the beat-stroke are referred to that point. 


\section{Discrete Succession.}

The fact that the maximal rate at which we can perceive sensations as clearly successive is approximately the rate at which a series of beats can be produced points to a close relation between the movement of the ballistic type and the perception of discrete succession. In the case of sound it is clear that the minimal interval between two sounds which are perceived as successive, is not determined by the necessary duration of a stimulus to the ear. A sound may be heard and its pitch determined when two vibrations are given. This gives a varying minimal length for perceived tone. ${ }^{1}$ From $C_{1}$ to $g^{4}$ this means durations varying from $60.6-0.63 \mathrm{sig}$. With this in mind Abraham and Schaefer ${ }^{2}$ made a series of experiments to determine how rapidly two tones might follow each other. Using a variety of musical intervals they found that the minimal interval between the tones is approximately the same for all octaves, and that the observed variations follow no regular curve. In all tones above $B_{1}$ the minimal interval in a trill or tremolo is longer than the time for the recognition of pitch. In octaves $c^{2}, c^{s}, c^{4}$, it is from eight to fifty times as long as the duration necessary for determining the pitch. In musical figures, the interval was rather longer than for trills and tremolos. The length of the interval for trills or tremolos was 28-42 sig.; for musical figures involving at least three pitches the minimal interval approximated 100 sig. This is also the range of the duration of a beat-stroke in a rhythm, and as Reif points out, the minimal interval in produced rhythms. Wundt gives the minimal interval as determined for various senses as from $16-47$ sig." Exner and Weyer found an anomalous value for hearing of 2-5 sig., which is probably not the interval of a true succession, but of some sensation quality. A continuation of a series at such an interval would, of course, produce a tone. Hylan gives the minimal interval for hearing for eight subjects

${ }^{3}$ Abraham, O., n. Brühl, I. J., Zeitsch. f. Psy. u. Phys. d. S. org., '98, 18, S. 177 ff.

Abraham, O., Scliaefer, K. L., 'Ưbex die Maximale Geschwindigkeit von Tonfolgen,' Ztschr. f. Psy. u. Phys. d. S. org., '99, 20, S. 403.

'Reif, loc. cil.

"Wundt, W., Grundzüge, 5te Aufl, Leipzig, '03, 3, S. 46. 
as ranging from 26-86 sig., average, 47 sig. ' The maximal interval for the appearance of a musical tone is variously given as $30-60$ sig.

When a sound stimulus flows in over the nerves, it is not heard, $i$. e., does not attain vividness and appear in consciousness, unless it obtains the reflex discharge shown in Fig. Io by the connection between $A$ and $D$. This reflex is the essential element in the 'attention' to the sound and is necessary to any motor theory of rhythmization of a sound series. This reflex is probably a contraction of both the positive and negative sets of the musculature (position and extent unknown); in the case of 'starting' at a sound, it even seems to be of the ballistic type. If the sound continues, the contraction and consequent tension between the muscle-sets continues unless inhibited by other processes (as when one fails to hear a familiar continuous sound). The reaction seems to be stronger at first than shortly after, and this gives a certain pulse to the earlier part of the sound. If the sound is short, this sudden contraction which gives a vividness of the pulsation type is the entire reaction, and the positive and negative muscles relax. The sudden contraction is the condition on which the pulse of the new sound-beat depends, it marks the new thing, and without it there can be no discrete succession. If the sound is repeated at short intervals, the motor reaction is thrown into the cyclic form. The most rapid form of cyclic movement in which the sudden contractions of the type necessary to discrete succession can be produced, is that of the double ballistic stroke as described by Richer and Rieger. This is the form which the motor reaction must take in perceiving a discrete succession at a maximal rate.

Some of the phenomena observed by Abraham and Schaefer and for which they offer no explanation are of the greatest interest in the light of this hypothesis. ${ }^{2}$ In judging musical figures containing three or more different pitches in succession, they found that at the most rapid rate the tones were heard as a chord; no succession was detected, although the stimulation 402.

'Hylan, J. P., 'The Distribution of the Attention,' Psy. REv., '03, 10, p.

2 Abraham and Schaefer, Loc. cit. 
was manifestly a matter of succession. In the resultant chord, the order was in no wise determined by the actual order in which the notes were given; moreover the notes were frequently mistaken. What the subjects did hear were the ordinary combinations of such tones into chords, and unusual notes were frequently replaced by more usual ones. Hylan has observed precisely the same thing in the case of visual sensations. Hylan's' explanation is that 'somewhere on the route of transmission the visual impulses from different points of the retina traverse paths sufficiently common to cause the impulses received first to overcome the inertia, thus allowing the later impulses to overtake the first and so to reach the center of consciousness nearly or quite simultaneously with them.'

But it seems to the writer more simple to refer the phenomenon to the fact that succession is the result of a distinct motor process requiring more time than the interval of the succession in question affords.

As the rate of the tone succession was gradually lessened, Otto and Schaefer found that a succession might be heard in which the material present was modified. Intermediate tones were often omitted outright, though their intensity equalled that of the other tones. In several cases alternate beats of the same tone were omitted; this happened with all the observers. This means that the motor process which orders these beats into succession and gives them the vividness by which they appear in consciousness may react so as to suppress or ignore every other beat in a uniform series. Frequently tones were not obliterated, but carried over to the next beat; e.g., the figure was heard when the interval of succession was 28 sig. as (at 95 sig. the figure was correctly perceived). This shows that the motor process has reduplicated upper notes and misplaced lower notes, carrying them over an entire beat. The motor process involved in the perception of such a series must consist of

3 Hylan, loc. cit., p. 403. 
ballistic strokes in opposite directions (or of ballistic strokes in the same direction, if more than two members are involved). If the movement of the motor process of the lower notes was running but half as fast as the objective beating, every other note coincided with each pulse (end of a beat-stroke) of the movement, and each intervening note occurred during a ballistic stroke. If the note occurs at the pulse of the movement, it will receive the vividness of a beat and appear in consciousness. If a note occurs during a ballistic stroke, it will either be lost, or it will be referred to the pulse at the end of the stroke. If the activity caused by the stimulation persists until the end of the stroke, the sound will be perceived at that point; if the activity of the stimulus dies out, then the sound is lost. In the cases just mentioned, where a tone appearing but once in the figure was not perceived, the stimulus must have died out before the end of the movement. In the cases where the sound was misplaced one beat the stimulus must have persisted. In the case of alternate sounds of the same pitch which seemed to be lost, it may be that they simply fused with the same sound occurring at the pulse of the movement.

Precisely the same phenomena in the case of sensations of sight connected with movements have been observed by Dodge ${ }^{1}$ and carefully studied by Holt. ${ }^{2}$ The movements of the eye in question are extremely rapid. Dodge and Cline give the duration of eye movements of 5-40 deg. as 34.5-100 sig., which agrees very well with the duration of the beat-stroke in the rhythm-movement. It has been demonstrated that a sensation of sight occurring during such a movement of the eye is not located during the movement, but at the point where the movement stops, just as the sensations of sound in a rhythmic beat-stroke are referred to the end of the stroke. By skilful management Holt reduced the intensity of the stimulation during the movement until the stimulation died out before the end of the movement was reached, and proved that such a

${ }^{1}$ Dodge, R., 'Eye Morements,' PSY. REv., ' $\infty$, 7, p. 454 ff.

'Holt, E. B., 'Eye Movement and Central Anesthesia,' Harvard Psy. Stud., I., 'o3, p. I ff.

'Dodge, R., and Cline, T. S., 'Eye Movements,' PSY. REv., 'Or, 8, p. 155. 
stimulation, though readily perceived by the eye at rest, is invisible when occurring during the movement. ${ }^{2}$ Holt explains this 'central anesthesia' by assuming localization centers in connection with the movements of the eye (corresponding to $B$ and $C$ of Fig. II, above) which discharge to the motor center of the muscles (corresponding to $D$ ). The vividness of the incoming visual sensation is produced by the discharge from the color centers (corresponding to $A$ ) to the localization center (B and $C$ ) and thence to the motor centers $(D)$. " During visual anesthesia muscular sensations of present movement are streaming to consciousness, to form the basis of the new post-motum localization." "And these would have to go * " to the localization, or eye-muscle sensation centers." "One may well suppose that the incoming centers are thus raised to such a tension that for the moment no discharge can take place thither from other parts of the brain, among which are the centers for color sensations" ( $i . c$., tension in $B$ so high that $A$ could not discharge into $B$ ). It is to be noted that this phenomenon in the case of visual sensations involves a temporal displacement exactly similar to that of the rhythmic process, and like the rhythmic displacement, it occurs in connection with the rapid movement, and only after it is well under way. Holt's explanation would be equally applicable to the cause of rhythmic displacement. But there is this objection. The cause of the high tension in $B$ (Fig. $\mathrm{II}$ ) is supposed to be the rapidly incoming currents from muscles and surfaces. In the eye, the epithelial surfaces may be supposed to furnish a large volume of such incoming sensations. But in the rhythmic movement the one point where a large number of intense sensations flow in is not during the movement, but at the close of the movement when sensations of strain, and perhaps of impact and sound, come in in large volume. It seems more probable that the disturbance of the temporal series is due to the peculiar innervation of the muscle-sets in the rapid movement, followed by the vividness due to the discharge at the close of the movement. Whatever the explanation, it should apply to rhythmic temporal displacement, to the theory of localization and motor anesthesia in the

'Loc. cil., p. 44. 
eye, to the maximal rate of succession, and to the omission of notes in rapid series as observed by Abraham and Schaefer.

It is remarkable that while the eye-ball is an extremely mobile organ, and many of its movements are expressly described as rhythmical ${ }^{1}$ its movements do not seem to lead to a perception of rhythm. Movements of the head and eyelids may be rhythmized, but the fact that the eye-movements have an essential part to play in another type of localization series seems to prevent the eye from figuring as an organ of rhythm.

In discussing the vexed question of simultaneity it is important to distinguish two distinct types; first, the type of simultaneity observed by Hylan in a very rapid succession of visual sensations (interval less than 20 sig.) and of sound sensations as observed by Abraham and Schaefer, on the one hand; second, the type of simultaneity which involves two coinciding rhythmic pulses, or two sensations located in two different temporal series, as in the well-known 'complication' experiments. In the case of simultaneity due to very rapid succession, the sensations simply enter consciousness en masse, and since they get but one motor reaction, they are not separated and have but one place in the temporal series. It probably happens that the succession in some cases gives the mass of sensations a peculiar sensory quality. Exner's anomalous interval with spark may have been of that type. In the experiments of Abraham and Schaefer it was often possible to determine that the chord was not a mere chord before any temporal succession could be detected. In the case of true temporal simultaneity, one temporal series is superposed on another temporal series, and a given sensation in the one series coincides with a given sensation in the other series. It is known that such coincidence is not determined by the objective relations, and that the ' attention' to the one or the other of the processes alters the reaction. ${ }^{2}$ This is probably due to the directness with which the sensations are connected with the motor apparatus, and the possibility of the one occurring during the beat-stroke time-gap of the other.

That such speculations do not represent the actual facts in the central process is more than probable. But however crude

${ }^{1} C f$. Dodge, P5y. REv., ' $\infty, 7$, p. 457 as to cye-movements in reading.

2 Wundt, Grundzüge, 5te Auf., 3, S. 86. 
or inexact such constructions may be, the investigation of certain aspects of rhythm, especially of the events during the movement-cycle and of the phenomena of temporal displacement and subjective accentuation, should be an excellent means of approach to the theoretical problems of succession and relative vividness. A rhythm can be controlled in detail, and its motor character adapts it to experimentation. 